RESEARCH

SERIES

NUMBER 81

March 2019

\title{
AN INITIAL EVALUATION OF THE EFFECTIVENESS OF INTREO ACTIVATION REFORMS
}

\section{ELISH KELLY, SEAMUS MCGUINNESS, PAUL REDMOND, MICHAEL SAVAGE AND JOHN R. WALSH}

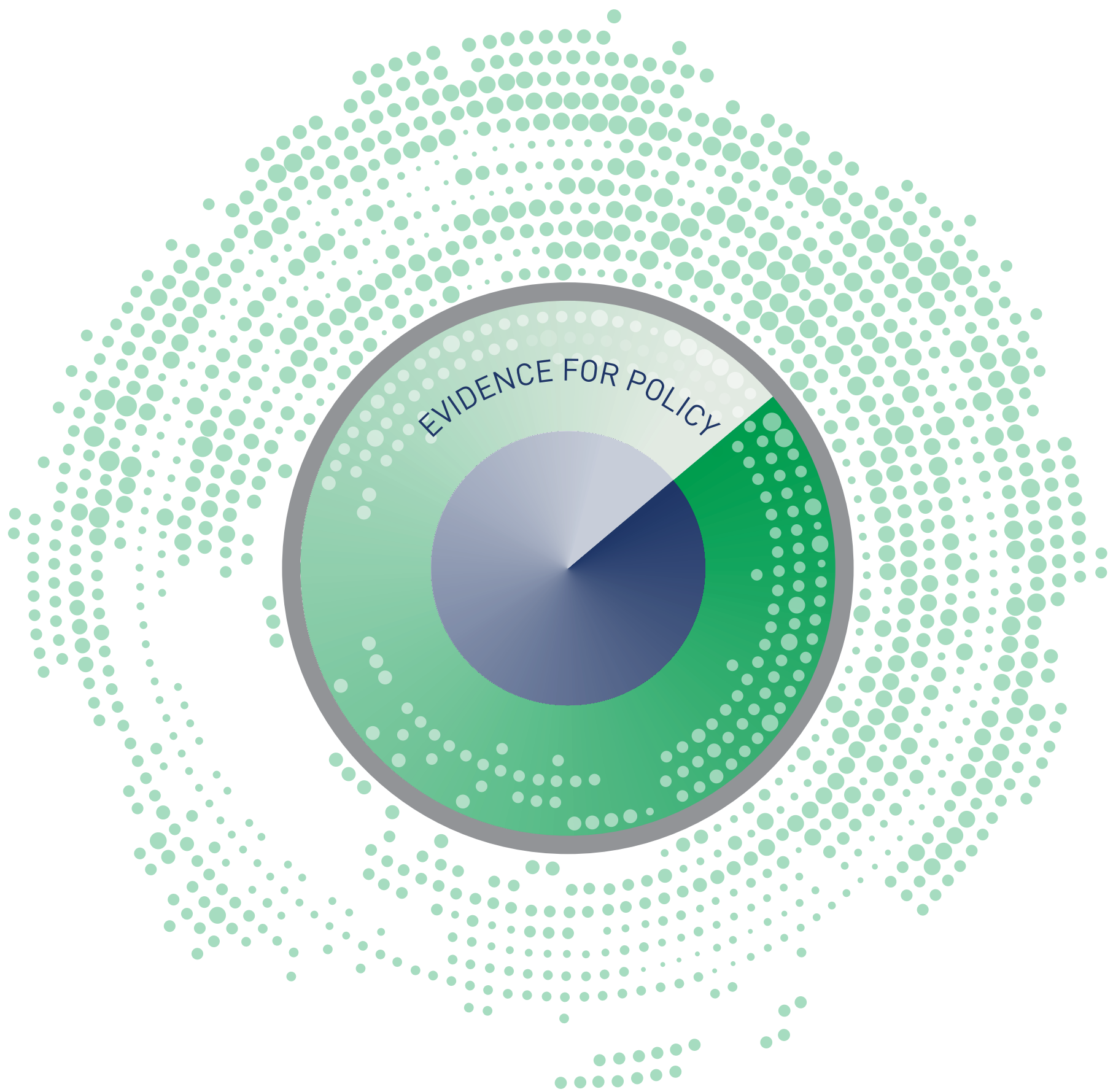




\title{
AN INITIAL EVALUATION OF THE EFFECTIVENESS OF INTREO ACTIVATION REFORMS
}

\author{
Elish Kelly \\ Seamus McGuinness \\ Paul Redmond \\ Michael Savage \\ John R. Walsh
}

March 2019

\section{RESEARCH SERIES NUMBER 81}

Available to download from www.esri.ie

(C) The Economic and Social Research Institute

Whitaker Square, Sir John Rogerson's Quay, Dublin 2

ISBN 978-0-7070-0472-3

DOI https://doi.org/10.26504/RS81

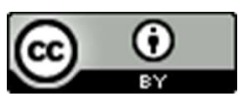

This Open Access work is licensed under a Creative Commons Attribution 4.0 International License (https://creativecommons.org/licenses/by/4.0/), which permits unrestricted use, distribution, and reproduction in any medium, provided the original work is properly credited. 


\section{ABOUT THE ESRI}

The mission of the Economic and Social Research Institute is to advance evidencebased policymaking that supports economic sustainability and social progress in Ireland. ESRI researchers apply the highest standards of academic excellence to challenges facing policymakers, focusing on 12 areas of critical importance to 21stcentury Ireland.

The Institute was founded in 1960 by a group of senior civil servants led by Dr T.K. Whitaker, who identified the need for independent and in-depth research analysis to provide a robust evidence base for policymaking in Ireland.

Since then, the Institute has remained committed to independent research and its work is free of any expressed ideology or political position. The Institute publishes all research reaching the appropriate academic standard, irrespective of its findings or who funds the research.

The quality of its research output is guaranteed by a rigorous peer review process. ESRI researchers are experts in their fields and are committed to producing work that meets the highest academic standards and practices.

The work of the Institute is disseminated widely in books, journal articles and reports. ESRI publications are available to download, free of charge, from its website. Additionally, ESRI staff communicates research findings at regular conferences and seminars.

The ESRI is a company limited by guarantee, answerable to its members and governed by a Council, comprising 14 members who represent a cross-section of ESRI members from academia, civil services, state agencies, businesses and civil society. The Institute receives an annual grant-in-aid from the Department of Public Expenditure and Reform to support the scientific and public interest elements of the Institute's activities; the grant accounted for an average of 30 per cent of the Institute's income over the lifetime of the last Research Strategy. The remaining funding comes from research programmes supported by government departments and agencies, public bodies and competitive research programmes.

Further information is available at www.esri.ie 


\section{THE AUTHORS}

Elish Kelly is a Senior Research Officer, Seamus McGuinness is a Research Professor, Paul Redmond is a Research Officer and John R. Walsh is a Senior Research Analyst at the Economic and Social Research Institute (ESRI). Michael Savage was a Research Officer at the ESRI when the research was undertaken. Dr Kelly, Professor McGuinness and Dr Redmond also hold adjunct research positions at Trinity College Dublin (TCD), and Professor McGuinness is a research fellow at the Institute of Labor Economics (IZA) in the University of Bonn.

\section{ACKNOWLEDGEMENTS}

The research undertaken in this report was funded by the Department of Employment Affairs and Social Protection. We would like to thank the individuals within the Department who provided assistance with queries during the project, including access to data and comments on earlier drafts of the report. In particular, we would like to thank Terry Corcoran, Hugh Cronin, Eric Doyle, ${ }^{1}$ Saidhbhin Hardiman, Ciaran Judge, Barry Kennedy and Kasey Treadwell-Shine ${ }^{2}$ for their active engagement with the project. We are also grateful to the independent reviewers who provided comments on an earlier draft of the report.

This report has been accepted for publication by the Institute, which does not itself take institutional policy positions. All ESRI Research Series reports are peer reviewed prior to publication. The author(s) are solely responsible for the content and the views expressed. 



\section{CONTENTS}

Executive Summary

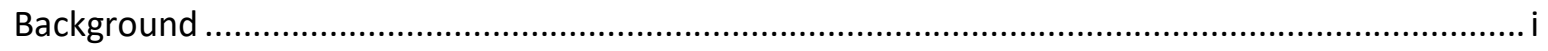

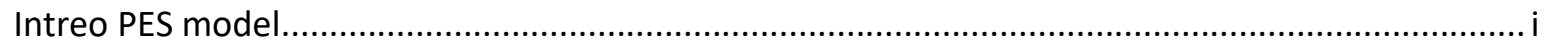

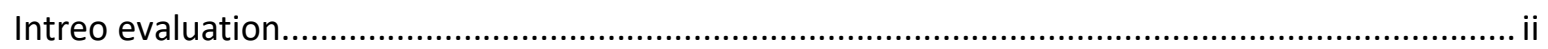

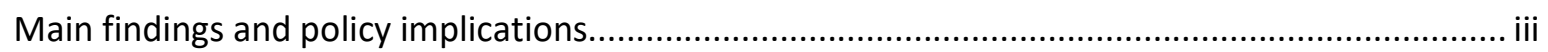

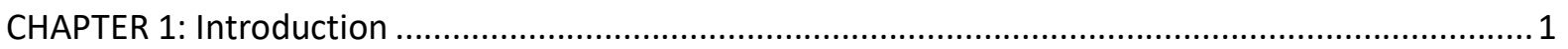

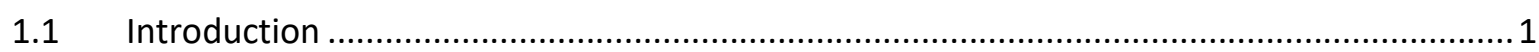

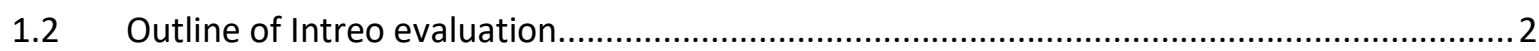

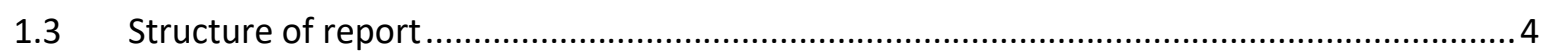

CHAPTER 2: Overview of reforms to Ireland's public employment services ......................................... 5

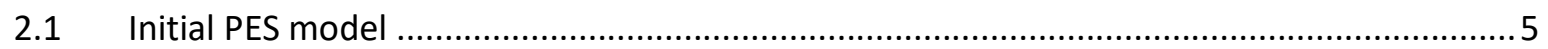

$2.2 \quad$ National Employment Action Plans PES model ............................................................... 5

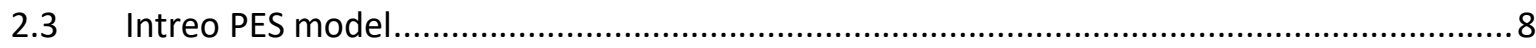

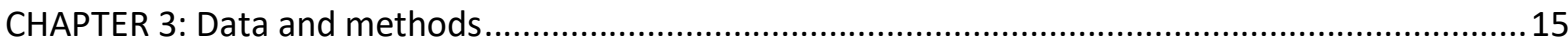

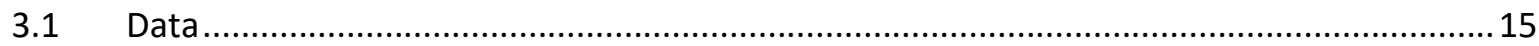

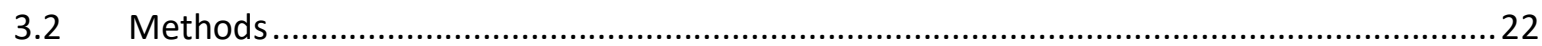

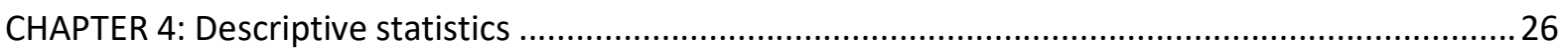

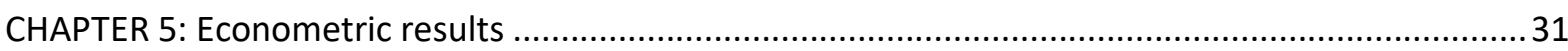

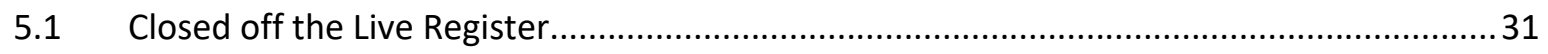







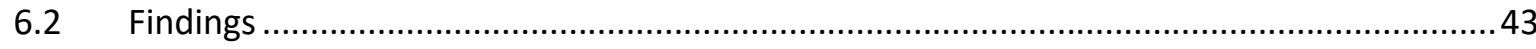

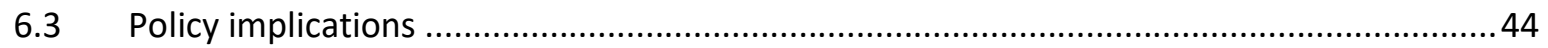

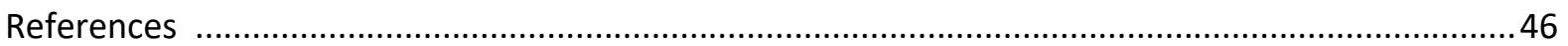

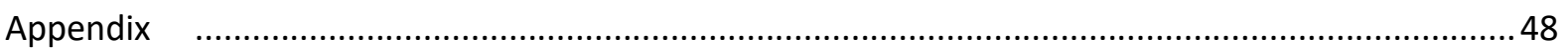




\section{LIST OF TABLES}

Table 3.1 Social welfare local offices used for Intreo evaluation .................................................17

Table 3.2 Geographical distribution of claimants across treatment offices...................................18

Table 3.3 Geographical distribution of claimants across control offices..........................................19

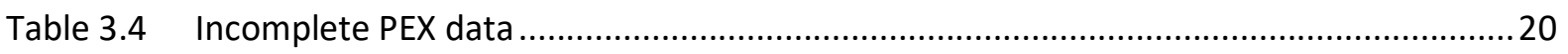

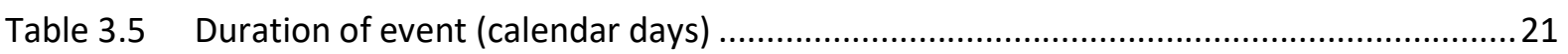

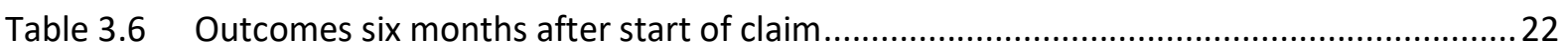

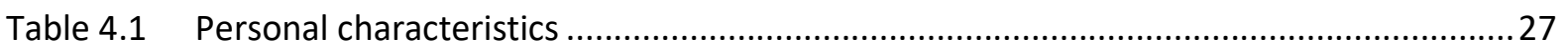

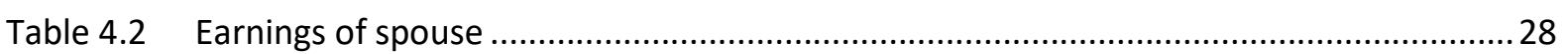

Table 4.3 Claimants' employment history prior to becoming unemployed....................................28

Table 4.4 Percentages in employment: 3, 6, 9 and 12 months after first claim...............................29

Table 4.5 Percentages in education or training: 3, 6, 9 and 12 months after first claim ................29

Table 4.6 Percentages in other outcomes: 3, 6, 9 and 12 months after first claim ........................30

Table 5.1 PSM-DiD results for probability of exiting the Live Register ..........................................33

Table 5.2 DiD coefficients from PSM-DiD analysis of probability of exiting the Live Register .........36

Table 5.3 PSM-DiD analysis of probability of being in employment............................................... 38

Table 5.4 PSM-DiD analysis of probability of being in education, training or employment

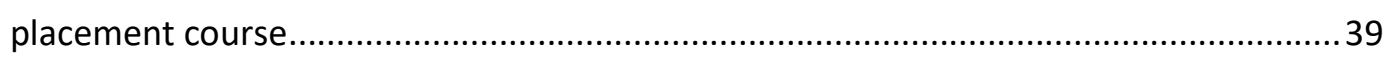

Table 5.5 PSM-DiD analysis of probability of being in the 'other' outcome category.....................40

Table 5.6 Distribution of outcomes within the 'other' outcome category....................................... 41

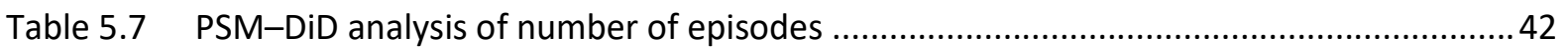

Table A1 Differences in personal characteristics among treatment and control groups ................ 48

Table A2 Differences in personal characteristics within treatment and control groups over time 49

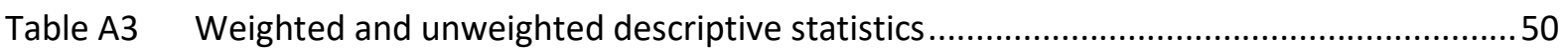

Table A4 Individuals with a Live Register history of less than 50 days' duration: DiD coefficients from PSM-DiD analysis of probability of exiting the Live Register..................................51

Table A5 Individuals with a Live Register history of less than 50 days' duration: PSM-DiD analysis of probability of being in employment .......................................................................... 52

Table A6 Individuals with a Live Register history of less than 50 days' duration: PSM-DiD analysis of probability of being in education, training or employment placement course ............53

Table A7 Individuals with a Live Register history of less than 50 days' duration: PSM-DiD analysis of probability of being in 'Other' outcome category ...................................................5

Table A8 DiD coefficients from PSM-DiD analysis of probability of exiting the Live Register (full

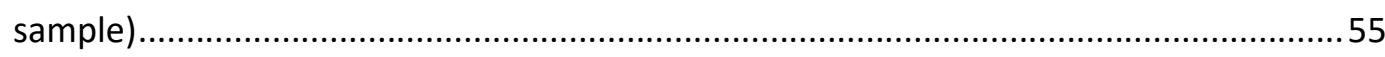

Table A9 PSM-DiD analysis of probability of being in employment (full sample)...........................5 55

Table A10 PSM-DiD analysis of probability of being in education, training or employment placement course (full sample) 
Table A11 PSM-DiD analysis of probability of being in 'other' outcome category (full sample) ......56

\section{LIST OF FIGURES}

Figure 2.1 National Employment Action Plan public employment services model....................... 8

Figure 2.2 Intreo public employment services model ..............................................................11 


\section{ABBREVIATIONS}

\begin{tabular}{|c|c|}
\hline ALMP & Active Labour Market Programme \\
\hline$A R$ & Activation Review \\
\hline BTEA & Back to Education Allowance \\
\hline BTWS & Back to Work Scheme \\
\hline CE & Community Employment \\
\hline CWS & Community Welfare Service \\
\hline DEASP & Department of Employment Affairs and Social Protection \\
\hline DSP & Department of Social Protection \\
\hline DiD & Difference-in-Differences \\
\hline ES & Employment Services \\
\hline ESO & Employment Services Officer \\
\hline ESRI & Economic and Social Research Institute \\
\hline GIS & Group Information Session \\
\hline GSW & Genuinely Seeking Work \\
\hline HSE & Health Service Executive \\
\hline$J A$ & Jobseeker's Allowance \\
\hline JB & Jobseeker's Benefit \\
\hline JLD & Jobseeker Longitudinal Dataset \\
\hline JSA & Job Search Assistance \\
\hline LCWO & Local Community Welfare Officer \\
\hline NEAP & National Employment Action Plan \\
\hline NEES & National Employment and Entitlement Service \\
\hline OLS & Ordinary Least Squares \\
\hline PES & Public Employment Services \\
\hline PEX & Probability of Exit \\
\hline PPP & Personal Progression Plan \\
\hline PSM & Propensity Score Matching \\
\hline PtW & Pathways to Work \\
\hline RMC & Record of Mutual Commitments \\
\hline SWA & Supplementary Welfare Allowance \\
\hline SWLO & Social Welfare Local Office \\
\hline TCD & Trinity College Dublin \\
\hline
\end{tabular}




\section{EXECUTIVE SUMMARY}

\section{BACKGROUND}

Ireland's public employment services (PES) have been undergoing restructuring since the mid-1990s. The country's initial PES model was predominantly focused on passive social welfare support with no, or relatively little, consideration given to either activation measures or employment services to assist jobseekers to enter/re-enter the labour market. Consequently, the objective of the reforms that have been introduced has been to move PES to a model underpinned by proactive activation as opposed to predominantly passive income supports.

The first set of PES reforms were implemented in 1997. Known as the National Employment Action Plans (NEAPs), these reforms focused on targeting certain groups of jobseekers and provision of employment services. Although the changes that were introduced were progressive, research conducted on their effectiveness found that the NEAP PES system was still too focused on passive income support. In addition, it was not successful in the delivery of efficient and effective services to jobseekers (e.g. Grubb et al., 2009; McGuinness et al., 2011).

Given the issues identified with the NEAP PES model, the government further reformed PES in 2011. The new PES model that was introduced was initially known as the National Employment and Entitlement Service (NEES), but it was subsequently renamed Intreo in October 2012. These most recent set of reforms have focused on changing how services are delivered to jobseekers. However, there have been no substantial changes to what employment services are delivered (i.e. Active Labour Market Programmes (ALMPs)).

\section{INTREO PES MODEL}

One of the key restructurings under the Intreo reforms has been the integration of the provision of benefit and employment services into one-stop-shop Intreo centres. Prior to this restructuring, jobseekers had to interact with three separate departments/agencies to access benefit and employment services (the Department of Employment Affairs and Social Protection (DEASP), Community Welfare Service (CWS) and FÁS).

A new case management system that links unemployment benefit payments to active engagement with jobseekers to support them into employment or training has been introduced as well. This engagement is underpinned by the principle of mutual obligation, whereby jobseekers are required to engage in job search and/or education, training or employment programmes in exchange for receiving benefit payments and efficient employment services. Under the new Intreo system, activation commences immediately (i.e. on the day that a jobseeker makes a 
benefit claim) as opposed to the jobseeker having to be unemployed for a certain period of time (three months) before being engaged with for the provision of employment services.

Prior to Intreo, the monitoring of jobseekers and the imposition of sanctions for failure to engage with PES were components of the NEAP model. However, neither was fully implemented (see Grubb et al., 2009; McGuinness et al., 2011). Now under Intreo, if a jobseeker fails to engage with PES he/she will be sanctioned. Their job search activity is monitored as well through regular compulsory engagement with an Intreo case officer. The frequency of this engagement is determined by the claimant's age and their risk of becoming long-term unemployed (i.e. their Probability of Exit (PEX) score - see Chapter 2): a new IT system introduced under Intreo uses these two pieces of information to independently determine the engagement pattern between the claimant and the DEASP.

In general, the ALMP and advice offered under Intreo are similar to what was provided under the NEAP system. Intreo, however, operates a work-first policy jobs first for those that are ready to enter/re-enter the labour market and education and training programmes for claimants who are not. To support this policy, there is now more regular engagement between the Department and local employers in order to encourage them to hire more individuals from the Live Register.

In summary, the new Intreo PES model consists of three main phases: (i) reception of jobseekers (i.e. activation activities on the day that a jobseeker presents at an Intreo centre to make a claim), (ii) integrated decision-making (e.g. decision on claim, calculation of PEX score), and (iii) active case management (e.g. one-to-one meeting with case officer, development of personal progression plan).

\section{INTREO EVALUATION}

The goal in implementing the Intreo PES process reforms has been to deliver more streamlined, efficient, effective and targeted PES that respond to jobseekers' needs. This report presents results from an initial evaluation of the effectiveness of the Intreo reforms in meeting this objective. Specifically, the evaluation identifies how the Intreo process reforms influenced various progression outcomes of jobseekers: (i) exits off the Live Register, (ii) exits to employment, (iii) exits to an education, training or an employment placement course, and (iv) exits to 'other' destinations. The evaluation is based on all new Jobseeker's Allowance (JA) and Jobseeker's Benefit (JB) recipients only. While the new approach to activation and engagement of jobseekers consists of three main phases, in this evaluation the various components of Intreo are treated as a single package of reforms.

The evaluation compares the progression outcomes of jobseekers who entered a new Intreo centre in the first six months of 2011 and 2013 against similar 
unemployment claimants who entered a standard social welfare local office (SWLO) that operated under the previous NEAP PES model during the same time periods. Based on international best practice, a difference-in-differences (DiD) methodology combined with propensity score matching (PSM) was the evaluation approach used to assess the effectiveness of the Intreo reforms.

Under the DiD-PSM methodology, the former group of offices that introduced the Intreo reforms are known as the treatment group, while the SWLOs that operated under the old NEAP PES system are the control group. The progression outcomes of these two groups are examined prior to the introduction of the Intreo reforms (April 2011-June 2012) and after the reforms had been implemented (April 2013June 2014).

\section{MAIN FINDINGS AND POLICY IMPLICATIONS}

In assessing the results from this study, it must be borne in mind that the evaluation was conducted at a time point early in the implementation of the new Intreo PES model, specifically one year after the reforms were put into operation. Thus, the evaluation is, at best, an assessment of the short-run effects of the Intreo PES reforms.

In conducting the analysis, we found that one of the cornerstones of the new Intreo PES system, the Probability of Exit (PEX) profiling model, was not properly implemented. The function of this component of the newly designed PES model was to rank jobseekers into low, medium and high PEX categories for activation, engagement and intervention by the DEASP according to an individual's risk of becoming long-term unemployed. However, when we examined the PEX information in the dataset that was provided by the Department for the evaluation, we found that 20 per cent of individuals in Intreo offices in 2013 did not have a PEX value.

In addition, of the individuals that received a PEX score, each had missing data for some of the profiling questions used to calculate the PEX value. This means that, if properly implemented, these claimants' scores were not usable for activation purposes and, therefore, should not have been used to segment individuals into different categories for engagement and intervention by the DEASP. Based on information provided by the Department, individuals with incomplete information should have been given a PEX value of zero. However, when we examined the data we found that this was not the case. These findings in relation to the PEX profiling model point to a potential process failure within the new Intreo PES system.

In conducting the evaluation, we also found that the control group, which consisted of a group of SWLOs that were implementing the NEAP PES system at the time of the evaluation, was not a valid counterfactual to use to compare the outcomes of the treatment group (i.e. the offices that were operating under the 
new Intreo PES model) against. Specifically, a key assumption of the DID evaluation framework is that, in the absence of the Intreo reforms, the treatment offices would display the same progression outcome trends as the control offices. However, a placebo analysis showed that this was not the case in the years prior to the introduction of the Intreo reforms.

On further investigation, the research suggests that differences in the geographic locations of the treatment and control offices are the reason why each group of offices displayed different progression outcomes in the years prior to the introduction of the Intreo forms. Specifically, four of the seven treatment offices were located in Dublin, with a fifth located in a neighbouring county (Bray, Co. Wicklow), while the control offices were mainly located along the western seaboard: two of the control offices were located in Cork, and one in each of Galway, Mayo, Donegal and Tipperary. There was only one control office in Dublin.

In an attempt to overcome this issue, we focused our analysis on treatment and control offices that were geographically close to each other. When we did this we found that, for the geographical sub-models that passed the placebo tests, there was weak evidence that the Intreo activation process reforms increased the probability of jobseekers exiting the Live Register at six, nine and 12 months following their initial claim.

For the geographical sub-model consisting of the Buncrana, Letterkenny, Sligo and Westport offices, there was weak evidence of an employment effect at six and nine months. However, the Intreo reforms were found to have no effect on the likelihood of a claimant entering an education, training or employment placement course. Given that the Intreo reforms focused on how PES were to be delivered (i.e. the processes) as opposed to what was delivered (i.e. ALMPs), it should not be too surprising that we found very small employment effects from the reforms and no education, training or employment placement course impact.

The Intreo reforms were found to increase a jobseeker's probability of exiting to the 'other' progression outcome category. This category, which was created by the DEASP and consists of approximately 150 subcategories, predominantly captures claimants who transferred to another DEASP payment or were no longer entitled to JA or JB. Thus, this result, which was found in both the overall model and the geographical sub-models, suggests that the Intreo reforms may have led to the early identification of invalid unemployment claims. If so, this may indicate efficiency gains from having benefit and employment services delivered in a 'onestop-shop' as opposed to the PES system being fragmented, as it was under the NEAP model. 


\section{CHAPTER 1}

\section{Introduction}

\subsection{INTRODUCTION}

This report presents results from an initial evaluation that the Economic and Social Research Institute (ESRI) has undertaken of the effectiveness of the most recent set of activation reforms that have been made to Ireland's public employment services (PES). The modifications, which are known as the Intreo activation process reforms, were first introduced in 2012 for all newly unemployed Jobseeker's Allowance (JA) and Jobseeker's Benefit (JB) recipients only. The reforms have focused on making changes to how benefit and employment services are delivered to jobseekers as opposed to what types of employment services are delivered (i.e., job search assistance, training, education courses, etc.).

One of the key restructurings that has been introduced into Ireland's PES has been the integration of the provision of benefit and employment services into 'one-stopshop' Intreo centres. ${ }^{3}$ Prior to this modification, jobseekers interacted with three separate organisations to access benefit and employment services:

1. the Department of Employment Affairs and Social Protection (DEASP), ${ }^{4}$ which managed the unemployment assistance payments and provided limited employment advisory services through its Jobs Facilitators;

2. The Community Welfare Service (CWS) of the Health Service Executive (HSE), which was responsible for the provision of temporary income support and Supplementary Welfare Allowance (SWA) payments while the main claim was being processed by the DEASP; and

3. FÁS, formerly Ireland's national training and employment authority, which provided training, work placements, apprenticeships and employment information services (i.e. Active Labour Market Programmes (ALMPs)) to jobseekers.

The introduction of the Intreo reforms, along with the other process changes that have been made to Ireland's PES, have been implemented with the intention of delivering more streamlined, efficient, effective and targeted PES that respond to the needs of jobseekers.

Although the Department with responsibility for those who are unemployed has been renamed, as of 1 September 2017, from the Department of Social Protection to the Department of Employment Affairs and Social Protection, it is not proposed to make any changes to the name of Intreo offices at present.

$4 \quad$ Known as the Department of Social Protection (DSP) until 1 September 2017. For further information on the new employment policy and labour law functions that the Department has taken on since this date, see https://www.welfare.ie/en/pressoffice/Pages/pr010917.aspx\# 
While labour activation reforms usually target specific services, Borghi and Van Berkel (2007) highlight a growing focus on operational reforms designed to improve administrative efficiency. As part of this process, the 'one-stop-shop' has emerged as a policy response to the problem of fragmented social security systems in Western Europe (Minas, 2014), as well as reflecting new ways of thinking about the provision of public services (Van Berkel, 2010). The United Kingdom (UK) was one of the first to introduce a 'one-stop-shop' for delivering benefit and employment services to its jobseekers: it did so in 2002 (Jobcentre Plus). Germany followed suit in 2004 (Bundesagentur für Arbeit) and France in 2009 (Pôle emploi) (Department of Public Expenditure and Reform, 2017).

While the adoption of such policies and their potential benefits and drawbacks are discussed in the literature, there is a lack of evidence on the effectiveness of these types of process reforms, such as the implementation of 'one-stop-shops', on labour market outcomes of unemployed people. In this report, we will help to fill this gap in the literature by evaluating whether the PES process reforms that have been introduced in Ireland (i.e. the Intreo reforms) have impacted the employment outcomes of jobseekers.

\subsection{OUTLINE OF INTREO EVALUATION}

The primary purpose of the evaluation conducted in this report is to identify how effective the Intreo activation process reforms, which are discussed in more detail in Chapter 2, have been in improving the likelihood of jobseekers exiting unemployment and, in particular, in exiting to employment. This new approach to activation and engagement of jobseekers consists of three main phases: (i) reception of jobseekers, (ii) integrated decision-making, and (iii) active case management. In this evaluation, the various components of Intreo are treated as a single package of reforms. ${ }^{5}$

Given the importance of PES in assisting the unemployed to reintegrate into the labour market, it is critical that any evaluation is carried out to the highest international standards. A difference-in-differences (DiD) methodology combined with propensity score matching (PSM) is the evaluation approach that is adopted in this study, selection of which was based on international best practice in the undertaking of such evaluations. The evaluation exploits variations in the roll-out of Intreo reforms over time in order to identify appropriate control and treatment offices. The PSM-DID methodology has been used in a large number of studies to evaluate the effectiveness of various labour activation programmes including, for example, job search assistance (Blundell et al., 2004; Centeno et al., 2009), general and specific skills training programmes (Stenberg and Westerlund, 2015), higher

\footnotetext{
5 Requirement set out in the Intreo evaluation Request for Tenders document.
} 
caseworker-to-client ratio (Hainmueller et al., 2011) and vocational training (Reis, 2015).

In this evaluation, we examine the extent to which the introduction of the Intreo PES activation process reforms has influenced various progression outcomes for jobseekers: (i) exits off the Live Register, (ii) exits to employment, (iii) exits to an education, training or an employment placement course, and (iv) exits to 'other' destinations. The evaluation is based on all new JA and JB recipients only. This is because when the Intreo processes were introduced in 2012 they concentrated initially on all newly unemployed JA and JB recipients. In the treatment and control offices examined in this evaluation, existing unemployed jobseekers continued to receive the standard National Employment Action Plan (NEAP) PES approach (see Chapter 2), which they would have commenced on becoming unemployed.

The evaluation compares the outcomes of claimants who entered a new Intreo centre (i.e. one of the social welfare local offices (SWLOs) that were among the first to adopt the Intreo process reforms in 20126) in the first six months of 2011 and 2013 against similar unemployment claimants who entered a standard SWLO that operated under the previous NEAP PES system (i.e. offices that adopted the Intreo process reforms after 1 July 2014) during the same time points. Under the DiDPSM methodology, the former group of offices are subsequently referred to as the treatment group, while the latter group are referred to as the control group. The progression outcomes of these two groups are examined prior to the introduction of the Intreo PES reforms (April 2011-June 2012) and after the reforms had been implemented (April 2013-June 2014).

One of the initial objectives of this study was to examine the impact of Intreo processes separately for jobseekers with different long-term unemployment risk levels. However, this proved not to be possible when the data received for the evaluation were examined. Specifically, the Live Register Probability of Exit (PEX) score, which ranks jobseekers into low, medium and high PEX categories for engagement and intervention by the DEASP according to an individual's risk of becoming long-term unemployed, is based on information that is gathered from claimants in the second phase of Intreo. This information is then inserted into an econometric profiling model (see O'Connell et al., 2009), which, as part of the Intreo PES reforms, was rolled out in SWLOs from 2011 onwards. When we examined the PEX information in the dataset that was provided by the DEASP for this evaluation, we found that 20 per cent of individuals in Intreo offices in 2013 did not have a PEX score. ${ }^{7}$ Furthermore, individuals that received a PEX value all 
had missing data for some of the profiling questions required to calculate the PEX score, rendering their scores unusable for activation purposes. ${ }^{8}$ In theory, individuals with incomplete profiling information should have been given a value of zero, but in examining the data we found that this was not the case. Given that the introduction of the PEX profiling model was designed to be one of the cornerstones of the newly designed approach to activation, the apparent failure to properly implement the system points to a potential process failure within the Intreo PES system.

The data provided by the Department for the evaluation were also not rich enough to support additional analyses of those who progressed into employment; specifically, in terms of examining the duration of such individuals' next employment spell, the earnings associated with their new job and the specific occupation that the individuals entered. When we examined the data, we found that approximately 40 per cent of those who exited to employment had a zero value for their subsequent employment counts/duration. Consequently, aspects of job quality could not be considered as part of the evaluation.

\subsection{STRUCTURE OF REPORT}

The remainder of the report is structured as follows. Chapter 2 outlines the main reforms that have been made to Ireland's PES. Chapter 3 provides a detailed description of the data used to evaluate the Intreo process reforms, along with the methodologies employed. Some descriptive statistics are presented and discussed in Chapter 4, while the econometric evaluation results are set out in Chapter 5. Finally, Chapter 6 provides a summary of the report, and also outlines the main conclusions that can be drawn from the evaluation. 


\section{Overview of reforms to Ireland's public employment services}

Ireland's PES have been undergoing restructuring since the mid-1990s. The intention of the changes that have been implemented has been to move PES to a model underpinned by proactive activation as opposed to predominantly passive social welfare supports.

\subsection{INITIAL PES MODEL}

Under the original PES model that operated in Ireland, which was in place until the introduction of the NEAP model in 1997, a jobseeker commenced their interaction with PES on the day that he/she entered their Social Welfare Local Office (SWLO; these offices are under the remit of the DEASP) to make a benefit claim. If the jobseeker had all the relevant information required to process their claim, he/she was fast-tracked to the Fresh Claims section. If not, then an appointment would be set up with the Fresh Claims section for a later date. Once claims were submitted, the Decisions section within the SWLO determined whether the claim would be awarded.

If a jobseeker required financial support while their claim was being processed, he/she was referred to the Community Welfare Service (CWS) of the Health Service Executive (HSE), who provided temporary income assistance. In this situation, the Local Community Welfare Officer (LCWO) immediately assessed the jobseeker's request and, if eligible, he/she would receive a weekly SWA payment until their unemployment benefit claim was decided.

Jobseekers were notified by mail if their claim was awarded, and were recorded as being unemployed as of the date they made their original claim. Once payment of their appropriate jobseeker payment had commenced, ${ }^{9}$ the claimant was entitled to a back-payment to the date of their original benefit claim. ${ }^{10}$

As can be ascertained from this description, Ireland's original PES model was entirely focused on passive social welfare support, with relatively little attention given to employment services to support jobseekers to enter/re-enter the labour market.

\subsection{NATIONAL EMPLOYMENT ACTION PLANS PES MODEL}

The National Employment Action Plans (NEAPs), which covered the period 1997 to 2011, were the first set of activation reforms that were undertaken to Ireland's 
PES. The amendments that were introduced focused on targeting certain categories of jobseekers and provision of employment services.

The NEAPs initially concentrated on those under the age of 25 that had been on the Live Register for six months, and were gradually extended to target all new entrants onto the Live Register during the 2000s. The Live Register threshold for intervention was reduced over time as well: from November 2006 onwards, individuals were pursued for employment assistance once they had been on the Live Register for three months.

Under the NEAP PES model, the DEASP identified all individuals aged 18-65 who had reached three months on the Live Register and referred them for a one-to-one counselling interview with a FÁS Employment Services Officer (ESO). During this interview, the ESO provided the jobseeker with guidance and job search assistance, along with possible referral to a job or access to a training, education or publicsector job creation scheme placement. After this interview, the jobseeker was required to adhere to the personal progression plan (PPP) drawn up with the ESO. However, follow-up engagement with Active Labour Market Programmes (ALMPs) was voluntary; thus, not all jobseekers followed their plan. For claimants who continued to engage with FÁS's employment services, the ESO and the jobseeker agreed an interview schedule to monitor the jobseeker's progress in the steps they had agreed the jobseeker would undertake to assist him/her to enter/re-enter the labour market. This engagement could include job search monitoring, but it was not formalised.

Attendance at the FÁS one-to-one interview was quasi-compulsory; thus, not all individuals referred by the DEASP to FÁS for employment assistance attended their interview. ${ }^{11}$ Jobseekers who did not attend, or who subsequently declined offers of training or other employment service assistance, were referred back to their SWLO for a DEASP Deciding Officer to determine if the jobseeker continued to satisfy conditions for receipt of their unemployment payment. ${ }^{12}$ If the SWLO Deciding Officer found that the claimant had valid reasons for not availing of the employment services that were being offered to him/her, the jobseeker continued to receive their benefit payment. In these situations, the DEASP Job Facilitators assisted jobseekers to identify barriers to participation and explored other labour market entry routes for the claimant. If the jobseeker's reasons for not attending the FÁS one-to-one interview were not deemed to be valid, then the jobseeker could be sanctioned. However, in practice this was not consistently applied.

11 There are various reasons why claimants may not have attended their one-to-one meeting with a FÁS ESO. For example, some jobseekers were able to access employment or training/education opportunities by their own efforts or by using the self-service facilities available in the FÁS employment service offices. Others had already found work/registered for a training or education course by the time that they received their referral letter. Others still may not have had the confidence to accept the offer of assistance, or were further away from the labour market and had basic literacy/numeracy difficulties or other personal issues (e.g. drug use) that prevented them from availing of the employment services offered to them (DSP, 2012).

12 In Ireland, jobseeker payment recipients are statutorily obliged to be available for and genuinely seeking employment (DSP, 2012). 
The reforms of the NEAP were progressive. In particular, they provided for greater and more systematic engagement with jobseekers through referral to a counselling interview with FÁS employment services. However, research conducted on the effectiveness of the NEAP PES model found that the system was not successful in delivering efficient and effective services to jobseekers, and that it was still too focused on passive income support as opposed to engaging more proactively with unemployed clients (Grubb et al., 2009; McGuinness et al., 2011). In particular, the lack of, or inconsistent use of, activation measures, such as requiring compulsory engagement with employment services, monitoring job-search activities and implementing a robust sanctions regime, was found to be a major flaw with the NEAP PES model.

In addition, several barriers to efficiency were highlighted with this system. Specifically, the NEAP PES model was identified as being quite fragmented due to the number of different departments and agencies involved in delivering benefit and employment services to jobseekers - the DEASP, CWS and FÁS (see Figure 2.1). This fragmentation resulted in different rules and processes being applied to deal with jobseekers' claims; control systems were fragmented; and assessment and control of claims were investigated separately by the DEASP and CWS, with different conditionality rules applied. Also, there was little data sharing across the organisations allowing for the effective tracking of a jobseeker through their claim period - from awarding of their benefit and their engagement with the various departments/agencies for employment services through to their exit from unemployment.

Additionally, after having their claim processed jobseekers were not engaged with again for the provision of employment services until they were unemployed for a minimum of three months. Furthermore, the ALMPs provided focused predominantly on direct employment schemes (e.g. Community Employment) and education courses with weak labour market linkages. There was also very little, if any, employer involvement in determining the types of education and training courses to be provided to jobseekers that would assist them to enter/re-enter the labour market. 


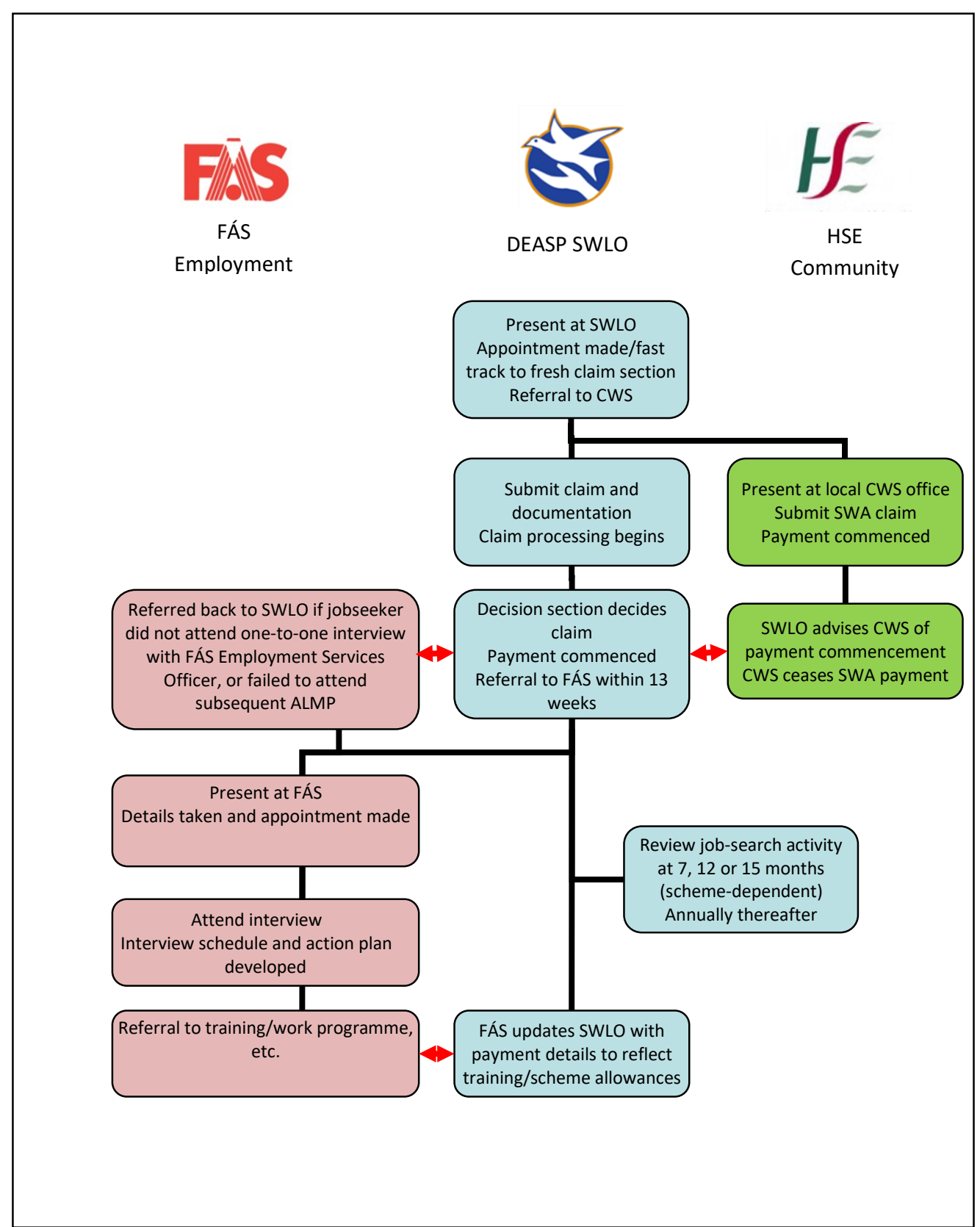

Source: DEASP.

\subsection{INTREO PES MODEL}

In response to the various issues that the research identified with the NEAP PES model, the government established a new PES model, the National Employment and Entitlement Service (NEES), in 2011. The rapid rise in unemployment that the 2008 global financial crisis, and subsequent Great Recession, gave rise to also contributed to the reforms that were implemented. The Programme of Financial Support agreement that was signed between Ireland and the EU/IMF to address Ireland's national debt played a role as well. Specifically, under this agreement the Government agreed to reform Ireland's PES (Department of Public Expenditure and Reform, 2017). This included improving activation measures, increasing incentives to work and strengthening sanctions for non-compliance with the job- 
search requirements for unemployment benefits (Department of Public Expenditure and Reform, 2017).

The name of the new PES model (i.e. NEES) was subsequently changed to Intreo in October 2012, which was when national roll-out of the new PES system commenced. The reforms that have been implemented to Ireland's PES under Intreo focus on how entitlement and employment services are delivered (i.e. the processes used) as opposed to what employment services are delivered (i.e. ALMP).

As mentioned in Chapter 1, one of the main process reforms made to Ireland's PES under Intreo has been the integration of the management of jobseekers' payments with employment services: the delivery of unemployment benefits, supplementary welfare and employment and activation services by the DEASP, CWS and FÁS respectively are now together under one roof (see Figure 2.2). These new 'onestop-shops', known as Intreo centres, are the responsibility of one government department, the DEASP. The amalgamation of these three departments/agencies was undertaken in order to facilitate the delivery of more streamlined PES. In addition, it is intended that the merger of the three organisations will reduce the time taken to process a jobseeker's claim and to lower the need to resort to temporary CWS income payments.

The Intreo PES reforms have also seen the introduction of a new case management system that links unemployment benefit payments to active engagement with jobseekers to support them into employment or training. This new form of engagement is implemented through the principle of mutual obligation, whereby benefit recipients are expected to engage in job search and/or education, training or employment programmes in exchange for receiving benefit payments and efficient employment services.

Under the new Intreo PES model, failure to engage with PES now results in jobseekers being sanctioned, which is a substantial reform of the NEAP regime: although sanctions and monitoring were components of the NEAP PES model, neither was implemented to any extent (see Grubb et al., 2009; McGuinness et al., 2011). Authority to implement reduced rates of pay was signed into law in the Social Welfare (Miscellaneous Provisions) Act 2010, and is applied when a jobseeker declines any type of PES intervention offered to him/her to assist them to enter/re-enter the labour market. ${ }^{13}$

13 A reduced rate of payment is applied for non-attendance after a jobseeker is warned of the consequences of not engaging and fails to attend a second intervention. 
In addition, under the new Intreo PES model jobseekers, specifically newly unemployed JA and JB claimants, are engaged with on the day that they make an unemployment benefit claim as opposed to having to be on the Live Register (i.e. unemployed) for a specified period of three months. Specifically, information is gathered from all new jobseekers on the day that they make their benefit claim, or on a day soon after, ${ }^{14}$ in order to calculate a score that identifies the jobseeker's likelihood of exiting the Live Register within 12 months (see O'Connell et al., 2009). This score, which is known as the Probability of Exit (PEX) score, and was mentioned briefly in Chapter 1 , is then used by the DEASP to segment jobseekers into three target groups (low, medium and high PEX) for determining engagement levels. This new tool, which is known as profiling, was introduced to improve the targeting of activation interventions.

Even if a jobseeker's PEX score is not calculated on the day that he/she makes an unemployment benefit claim, engagement between the DEASP and the jobseeker commences straight away. Specifically, on their first day in an Intreo centre jobseekers receive information on a Group Information Session $(\mathrm{GIS})^{15}$ that they have to attend. GISs are usually scheduled three weeks after a claimant's initial engagement with an Intreo officer. The GIS is a briefing session during which the activation process is explained to the jobseeker. If claimants do not attend the GIS, they are contacted to attend their nearest Intreo centre and receive a verbal warning if they do not have an appropriate explanation for non-attendance. If a claimant fails to attend a GIS for a second time, he/she is given a penalty rate. Approximately 30 people are invited to each GIS, which is undertaken with the intention of achieving a minimum of 20 attendees. On their first day, claimants are also given information about the support that they will receive from the DEASP, their role in the PES activation process and what will happen if they do not actively engage with the DEASP. benefit claim, which could happen if a jobseeker does not have all the documentation required to proceed with such a meeting, this appointment will be organised for a date soon after the initial claim. 


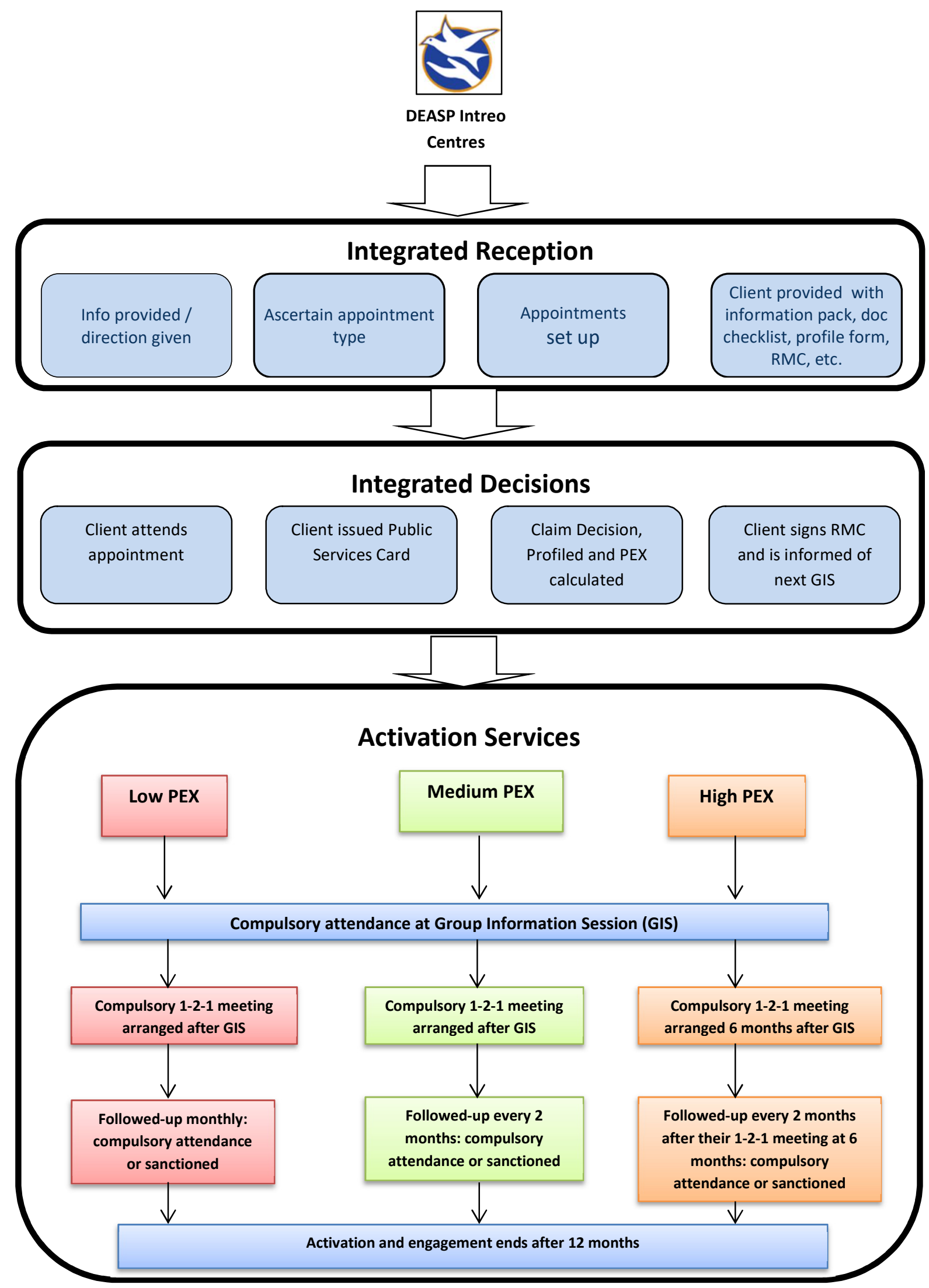


Activation commences at the GIS. Specifically, claimants are assigned a case officer and are given an appointment letter for a one-to-one meeting with this person. A new IT system introduced under Intreo, using claimants' PEX score information, independently determines the engagement pattern between the claimant and the DEASP: ${ }^{16}$ under the NEAP, the engagement pattern was determined by the ESO. Claimants with a low PEX score (i.e. low likelihood of exiting the Live Register) are seen monthly, as are claimants aged under 25. Medium PEX score individuals are engaged with every two months. After the GIS, high PEX score individuals are not engaged with again for six months and then these individuals are engaged with every two months. ${ }^{17}$ This engagement pattern is a 'minimum' engagement pattern as people can walk into an Intreo office and seek assistance at any time: claimants could independently walk in for employment services under the NEAP PES model as well.

Case officers work with their claimants to develop PPPs that outline the steps that will be taken to move the claimants from unemployment to a job. This could include JSA, training, job placement, etc. PPPs were developed under the NEAP PES system too; however, under Intreo the PPPs specify regular compulsory follow-up review meetings, which have sanctions attached if not attended by the claimants. Thus, as indicated previously, under Intreo income support has been made conditional on participation in activation/case management processes.

In general, the ALMP offered under Intreo, and advice, are similar to that provided under the NEAP PES model. Intreo, however, operates a work first policy - jobs first for those that are ready to enter/re-enter the labour market, and education and training for claimants who are not. To support this principle, there is now more systematic engagement with local employers to encourage hiring from the Live Register under the Intreo PES model, which did not operate under the NEAP system. Thus, as well as facilitating a single point of contact for jobseekers, Intreo centres facilitate a single point of contact for local employers. For the most part, ALMP under the NEAP PES model focused on training, education and public-sector job creation scheme referrals.

Under the Intreo PES model, the actual number of claimants assisted, and the time period when they are engaged with, depends on resource availability within each Intreo centre: the same applied under the NEAP PES model.

Under Intreo, activation and engagement end with claimants after 12 months. Again, this is determined centrally by the DEASP's new IT system, and then implemented by the local Intreo office. At this time point, signing on the Live

16 Intreo centres can determine the quantity of jobseekers that are referred to the case officers within their centre. However, the selection of jobseekers sent to their case officers is determined independently by the new IT system that the DEASP introduced, which is operated centrally in Carrick-on-Shannon.

17 Some Intreo centres run separate GIS for high PEX individuals, to account for their needs being different to low and medium PEX claimants. 
Register is reinstated for low and medium PEX jobseekers and they are required to engage in intensive job search for six months: high PEX claimants are not required to attend their Intreo office for the first six months. If jobseekers continue to be unemployed after this time period, a Genuinely Seeking Work (GSW) meeting is held with their Intreo case officer for their claim to be reassessed. This GSW meeting is a condition for eligibility for a jobseeker's social welfare payment. In more recent times, the long-term unemployed are referred to JobPath, a relatively new DEASP employment activation programme that is aimed at helping the longterm unemployed, and those furthest from the labour market, back into work. This employment programme is operated by two private providers. ${ }^{18}$

The process reforms to Ireland's PES that were introduced under Intreo were developed further under the Government's Pathways to Work (PtW) strategies. The first of these strategies was launched in 2012, with updates in 2013, 2015 and 2017. The PtW strategies were designed to complement the Government's Action Plan for Jobs strategies, both of which had the aim of addressing the jobs and unemployment crises that emerged after the Great Recession. The PtW strategies focus specifically on making sure that as many as possible of the new jobs that are being created in the economy, and any vacancies that arise, are being filled by unemployed jobseekers. The most recent PtW strategy, Pathways to Work 20162020 (DEASP, 2017), sets out measures to extend the approach of activation from unemployed jobseekers only to people with disabilities and lone parents. In general, the PtW strategies set out a range of targets, actions and objectives to enhance Ireland's PES with the intention of ensuring that the system is efficient and effective in helping jobseekers to transition out of unemployment and into the labour market.

In summary, the Intreo process can be categorised into three main phases: (i) reception of jobseekers, (ii) integrated decision-making, and (iii) active case management.

In phase (i), jobseekers present at an Intreo centre to make a claim. During this time, they register with the Employment Services (ES). They are also provided with a checklist for their appointment, which may take place that day if the jobseeker has all the required documentation, and a copy of the Record of Mutual Commitments (RMC). The RMC outlines the responsibilities of both the DEASP, via the Intreo centres, and the jobseeker. In the RMC, Intreo centres commit to finding suitable employment or training for the jobseeker through a PPP. The jobseeker commits to engage with Intreo services, attend meetings arranged by their case officer and take up activation programmes suggested by Intreo. 
In phase (ii), the PEX score, which measures an individual's likelihood of becoming long-term unemployed, is calculated for the jobseeker and they are given information about the GIS. The jobseeker also signs the RMC.

In phase (iii), the jobseeker will attend the GIS, during which time a one-to-one meeting will be arranged with a Case Officer. During this meeting, the jobseeker agrees a PPP and may be offered a range of activation opportunities.

Progress towards the jobseeker's PPP goals is monitored through regular Activation Review (AR) meetings, the frequency of which is determined by the jobseeker's age and PEX score. As mentioned previously, a more stringent sanctions regime is in operation under Intreo, whereby failure to attend an appointment with their case officer results in the client being brought into the Intreo centre to explain, and given a warning. If the jobseeker fails to attend the subsequent appointment, the deciding officer may impose a reduced rate of payment. Continued failure to engage will result in a disqualification of the payment. 


\section{CHAPTER 3}

\section{Data and methods}

\subsection{DATA}

The DEASP provided anonymised data to the ESRI for the purpose of carrying out an initial evaluation of the Intreo activation process reforms. The data, which were extracted from the Department's Jobseeker Longitudinal Dataset (JLD) ${ }^{19}$ contain information on a person's social welfare claim history, along with their employment, training and activation episodes over time.

Data were provided for 14 social welfare local offices (SWLOs) for the years 2011 and 2013. The specific offices that were selected, along with the years, were necessary for the difference-in-differences (DiD) methodology that we employed to evaluate the Intreo PES reforms. As is discussed in more detail in Section 3.2, this evaluation methodology is based on identifying SWLOs that introduced Intreo activation process reforms in 2012, which will be referred to as the treatment group in this study, and offices that did not introduce the reforms and were therefore still operating under the NEAP PES model, which will be known as the control group, and comparing the Live Register exit outcomes of the two groups of offices at different points in time.

With the DiD methodology, the initial comparison in the outcomes of the treatment and control group SWLOs is based on a year prior to the introduction of the Intreo reforms. Given that the reforms were introduced in 2012, 2011 was selected for this initial outcome examination. In 2011, none of the selected 14 SWLOs had implemented the Intreo reforms. However, by 2013 seven of the 14 offices (our treatment offices) had implemented the reforms while the other seven (our control offices) had not. In order to evaluate the effectiveness of the Intreo process reforms, a second comparison in the Live Register outcomes of the treatment and control offices was undertaken in 2013, a year after the reforms had been implemented in the treatment offices.

Details of the offices that form our treatment and control groups are shown in Table 3.1. Seven treatment offices were identified as having implemented the reforms in 2012. Selection of these seven offices by the DEASP as the first to implement the Intreo reforms was based on the physical infrastructure of the offices, along with the amount of work needed to convert them into 'one-stopshops' and local human resource availability. Thus, the selection process was not based on these offices being located in geographic areas with the highest level of

19 For further information on this dataset, see Kelly et al. (2015). 
need or other such strategic criteria.

We were restricted to the seven control offices that appear in Table 3.1 on the basis that the control group offices, in order to meet the underlying criteria of the DiD methodology, could not have implemented the Intreo reforms prior to the outcome period examined in 2013/2014. Specifically, we did not want spill-over of the treatment (i.e. Intreo reforms) into the control offices. Based on the information provided to us by the DEASP, the control offices listed in Table 3.1 were the only offices that met this implementation criterion, as they did not implement the Intreo reforms until after 1 July 2014.

While all DEASP staff were made aware of the roll-out of Intreo, training to implement the new PES system was not provided to staff in the control offices until the roll-out commenced in their office. ${ }^{20}$ Thus, there was no potential spill-over of the treatment in the control offices through this channel. In addition, the DEASP checked and confirmed that no claimant in the data provided for the evaluation had switched from a treatment to a control office. In theory, jobseekers must make their claim and be activated in the welfare office located within their dwelling catchment area, whether that was an Intreo centre or a standard SWLO during the time period covered by this evaluation. However, a jobseeker's claim may be transferred to a new office in a different geographic location if the claimant changes their dwelling location. In such instances, the jobseeker is assigned to a case officer within the new office for continuation of their activation plan. Nevertheless, in order to ensure that there was no potential contamination from such switches in the evaluation conducted in this report, the Department removed any claimants who had switched office from the data provided for the study.

Another potential concern relates to the possible contamination of the treatment group, i.e. we must ensure that individuals in the treatment offices who made claims in 2011 did not fall under Intreo regimes before 12 months of their claim had elapsed. The DEASP provided information that the Intreo roll-out did not occur in the treatment offices until the second half of 2012. Therefore, to prevent contamination, we restrict our analysis to individuals who started their claim in the first six months of 2011. As such, even observing these individuals 12 months after their claim (up to the end of June 2012), we can be sure that they did not benefit from the Intreo PES reforms. 


\begin{tabular}{|l|l|}
\hline \multicolumn{2}{c}{ Years in which Intreo reforms were implemented } \\
\hline $\mathbf{2 0 1 2}$ (treatment offices) & $\mathbf{2 0 1 4}$ and later (control offices) \\
\hline Ballymun (Dublin) & Carrigaline (Cork) \\
\hline Bray (Wicklow) & Hanover Street (Cork) \\
\hline Buncrana (Donegal) & Galway \\
\hline Coolock (Dublin) & Letterkenny (Donegal) \\
\hline King's Inns Street (Dublin) & Nutgrove (Dublin) \\
\hline Sligo & Thurles (Tipperary) \\
\hline Tallaght (Dublin) & Westport (Mayo) \\
\hline
\end{tabular}

For each claimant, we have data on characteristics including gender, age, marital status, earnings of the spouse, nationality (Irish or non-Irish), number of dependent children and previous occupation, as well as on the number and duration of previous employment and Live Register spells (prior to the individual's current claim) and pre-Intreo Public Employment Services (PES) training. In our econometric models (Chapter 4), we also include a local unemployment rate measure to control for variations in local labour market conditions between the treatment and control offices.

The dataset provided to us by the DEASP for this evaluation contained information on 62,838 claimants in 2011 and 2013. However, as our analysis focuses on new entrants to Intreo offices, we focused only on individuals with no Live Register history, of which there were 18,189 cases. In addition, there were 487 cases who, although not recorded as having a Live Register history, were listed as having a previous episode in the past month involving either some type of labour market intervention or DEASP payment. Of these claimants, 158 (32 per cent), were recorded as having had an episode with FÁS. One Parent Family Payments and Specific Skills Training accounted for a further 26 per cent and 16 per cent of these cases respectively. The remaining individuals came from a wide variety of episodes including, for example, Community Employment (CE) schemes, Back to Education Allowance (BTEA), Back to Work Scheme (BTWS) and JobBridge. We excluded these 487 cases with an intervention in the previous 30 days, and were therefore left with a sample of 17,702 new Jobseeker's Allowance (JA) and Jobseeker's Benefit (JB) claimants. This sample represents our baseline specification. However, we also conducted sensitivity tests to check whether our results are robust to alternative specifications, one of which involved estimating our models using the full sample of 62,838 claimants. When we did this we found that our results remained consistent across various specifications.

With regard to the subsequent outcomes of claimants, we have data on whether they were in employment, on the Live Register or in education or training at intervals of three, six, nine and 12 months following their claim. We also have data 
on individuals who exited the Live Register for 'other' reasons, such as being transferred to another DEASP scheme or no longer being entitled to JA or JB.

Of the 17,702 individuals in our sample, 8,414 (48 per cent) are claimants from a treatment office and 9,288 (52 per cent) are from control offices. Tables 3.2 and Table 3.3 show the distribution of claimants across offices for the years 2011 and 2013. In the treatment offices, the Tallaght and King's Inns offices combined account for approximately half of the observations. The distribution was relatively stable over the two periods.

\begin{tabular}{|l|c|c|}
\hline Office & $\mathbf{2 0 1 1}$ & $\mathbf{2 0 1 3}$ \\
\hline Ballymun & $5.81 \%$ & $6.61 \%$ \\
\hline Bray & $n=260$ & $n=260$ \\
\hline Buncrana & $15.07 \%$ & $15.57 \%$ \\
& $n=675$ & $n=613$ \\
\hline Coolock & $5.20 \%$ & $5.23 \%$ \\
& $n=233$ & $n=206$ \\
\hline King's Inn Street & $13.24 \%$ & $13.69 \%$ \\
& $n=593$ & $n=539$ \\
\hline Sligo & $21.42 \%$ & $21.24 \%$ \\
& $n=959$ & $n=836$ \\
\hline Tallaght & $9.96 \%$ & $9.93 \%$ \\
& $n=446$ & $n=391$ \\
\hline
\end{tabular}
combined account for almost 65 per cent of observations. Again, the distribution remained relatively stable across the two time periods. 


\begin{tabular}{|l|c|c|}
\hline \multicolumn{1}{|c|}{ Office } & $\mathbf{2 0 1 1}$ & $\mathbf{2 0 1 3}$ \\
\hline Carrigaline & $5.15 \%$ & $5.04 \%$ \\
\hline Cork - Hanover Street & $n=274$ & $n=200$ \\
\hline Galway & $37.80 \%$ & $36.32 \%$ \\
& $n=2,011$ & $n=1,441$ \\
\hline Letterkenny & $25.28 \%$ & $24.87 \%$ \\
\hline Nutgrove & $n=1,345$ & $n=987$ \\
\hline Thurles & $7.88 \%$ & $8.39 \%$ \\
& $n=419$ & $n=333$ \\
\hline Westport & $15.17 \%$ & $17.16 \%$ \\
& $n=807$ & $n=681$ \\
\hline
\end{tabular}

Source: JLD.

While the JLD is a very rich data source, these data were due to be augmented for the Intreo evaluation with additional personal characteristic information that the Department gathers on all new social welfare claimants through its profiling system, which, as indicated previously, was rolled out in SWLOs from 2011. This system, which produces the PEX score that the DEASP uses to segment jobseekers into categories for activation engagement (low, medium and high PEX groups), was discussed in detail in Chapter $2 .{ }^{21}$ The answers to the 30 PEX questions that provide data for the profiling model relate to a claimant's educational attainment, labour market history, unemployment benefit history, literacy and numeracy difficulties, health, access to public transport, etc. The data also contain the actual PEX score that is derived for each claimant.

While the PEX information presents a potentially rich source of data, it was not possible, for a number of reasons, to fully utilise these data in our analysis. The main issue, as mentioned in Chapter 1, related to the limited coverage of PEX data. While 90 per cent of individuals in treatment offices in 2013 had a PEX value, the corresponding figure for control offices was 75 per cent. ${ }^{22}$ In 2011, just 38 per cent of individuals in treatment offices and 30 per cent of individuals in control offices had a PEX value. This latter finding is due to the fact that roll-out of PEX was not fully implemented in 2011, and its subsequent implementation was mainly concentrated, as one would expect, in Intreo offices. Nonetheless, it appears that 10 per cent of individuals in the treatment offices who should have had PEX scores did not.

\footnotetext{
21 For further information on the Department's use of the PEX model, see: http://www.welfare.ie/en/downloads/pathwaystowork.pdf

22 These statistics relate to our restricted sample of 17,702 new claimants.
} 
In examining the PEX data, we also found an issue relating to the completeness of data for the PEX questions. An individual's PEX score should be calculated based on their response to 30 PEX questions. We were provided with data from the Department that contained 30 variables that correspond to the 30 PEX questions. However, no individual with a PEX score had complete data on all 30 questions. This suggests that individuals had varying minimum and maximum possible PEX scores depending on the questions answered and, as such, the scores could not be directly compared with each other. The extent of the missing data is shown in Table 3.4, which shows the frequency of the number of incomplete questions. For example, 49 per cent of those with a PEX value have missing data relating to eight of the PEX questions.

The identification of these PEX data issues is a concern given that, since 2012, the PEX model, as discussed in Chapter 1 , has been a key component in the Department's toolkit for segmenting jobseekers into different groups (low, medium and high PEX) for activation engagement and intervention: it was also a cornerstone in the Pathways to Work (PtW) strategy that the Department devised to address the unemployment crisis that arose after the Great Recession in 2008.

\begin{tabular}{l|c|c|}
\hline Incomplete PEX questions (out of 30) & $\%$ \\
\hline 22 & 0.01 \\
\hline 21 & 0.01 \\
\hline 17 & 0.01 \\
\hline 15 & 0.01 \\
\hline 12 & 0.01 \\
\hline 11 & 0.03 \\
\hline 10 & 3.11 \\
\hline 9 & 20.76 \\
\hline 8 & 48.74 \\
\hline 7 & 21.06 \\
\hline 6 & 3.12 \\
\hline 5 & 0.27 \\
\hline 4 & 0.51 \\
\hline 3 & 1.49 \\
\hline 2 & 0.79 \\
\hline 1 & 0.09 \\
\hline Tource: $J L D$ & & 100 \\
\hline
\end{tabular}

One of the PEX questions captures a person's highest educational attainment, which is an important control variable in analysis of labour market outcomes. However, for the reasons stated above, this piece of information could not be used in this evaluation study. In an attempt to overcome this issue, the Department 
provided another source of education data, which were collected separately to the PEX questions. ${ }^{23}$ However, analysis of these other data revealed some issues that made them unusable. While the coverage of this other education data source was greater than the PEX data, there were still a large number of claimants with missing information. In 2013, no education data were available for approximately 40 per cent of individuals in both the treatment and control groups. The corresponding figures for missing data in the treatment and control groups in 2011 were 30 per cent and 36 per cent respectively.

A more serious issue than the limited data coverage was the systematic differences that were found to exist between the individuals for whom education data were provided and those for whom no education data existed. Table 3.5 compares the duration of the unemployment event (in calendar days) for individuals in the two groups, using the combined 2011 and 2013 data. ${ }^{24}$ The average duration of a claimant's unemployment event is substantially higher for the group with education data than for the group with no education data (360 days compared to 197 days). As such, it appears that the group with education data face significantly greater labour market disadvantage compared to the group without education data. In fact, information provided by the DEASP on the collection of this education data supports this. Specifically, these education data were gathered by the case officers who only engaged with jobseekers when they had been unemployed for more than three months. Given this, individuals with no education data would have had higher exit rates from unemployment to employment. Thus, they would not be as disadvantaged, in terms of ability to access the labour market, as the group with education data who were unemployed for a minimum of three months.

TABLE 3.5 DURATION OF EVENT (CALENDAR DAYS)

\begin{tabular}{|l|c|c|c|c|}
\hline Education data available & Mean (days) & Min (days) & Max (days) & Observations \\
\hline No & 197 & 1 & 1889 & 6,351 \\
\hline Yes & 360 & 1 & 1916 & 11,351 \\
\hline Total & 302 & 1 & 1916 & 17,702 \\
\hline
\end{tabular}

Source: JLD

This disadvantage is reinforced when we examine the outcomes of the groups (i.e. those with and without education data). In Table 3.6 we show the outcomes of both groups six months after the date of their initial unemployment claim. While a similar pattern is observed for three, nine and 12 months, for brevity we just show the six-month outcomes. It is clear that the group for which education data exist have much less favourable outcomes than the group without education data. For

23 These other education data came from the Department's Client Services System (CSS).

24 An event relates to a claim of either JA or JB. 
example, just 20 per cent of the group with education data are in employment six months after the start of their claim, compared to 49 per cent of the other group.

\begin{tabular}{|l|c|c|c|c|}
\hline & \multicolumn{3}{|c|}{ Education Data } & \multicolumn{3}{|c|}{ No Education Data } \\
\hline & Freq. & $\%$ & Freq. & $\%$ \\
\hline Closed off Live Register for other reasons & 456 & 4.02 & 511 & 8.05 \\
\hline In education, training or employment placement courses & 826 & 7.28 & 222 & 3.50 \\
\hline In employment & 2,270 & 20.00 & 3,121 & 49.14 \\
\hline On Live Register & 7,799 & 68.71 & 2,497 & 39.32 \\
\hline
\end{tabular}

In the absence of usable educational attainment information, we use a variable that captures a person's previous occupation (prior to their current claim). This will act as a proxy for educational attainment as the person's previous occupation and their education levels will be correlated. For example, those classified as managers and professionals will likely be educated to tertiary level.

\subsection{METHODS}

In this analysis, the impact of the introduction of the Intreo process reforms is estimated using a difference-in-differences (DiD) approach. We use cross-sectional data from 2011 and 2013. In each year, we observe two groups of individuals jobseekers from Intreo offices (the treatment group) and jobseekers from nonIntreo offices (the control group). To examine the effect of the reforms on the likelihood of claimants exiting the Live Register to employment, for example, the DiD estimator involves measuring the change in employment probabilities before and after the introduction of the Intreo process reforms, i.e. in 2011 (pre) and 2013 (post), in both the treatment and control groups.

The DiD estimate of the Intreo employment effect is then obtained by subtracting the difference in the outcomes in the treatment group from the difference in the outcomes in the control group. If we observed a large increase in employment probabilities in the treatment group, while at the same time observing no change in the employment probabilities in the control group, then we would get a positive DiD employment estimate which would indicate that the reforms increased a person's likelihood of finding a job. However, if we observed an increase in the treatment group's employment probabilities and a similar increase for the control group's, this would indicate that the Intreo reforms had no employment effect.

More formally, the DiD estimator can be described as follows. We identify two 
groups within the population of jobseekers: those that were claimants in the Intreo $\mathrm{SWLOs}^{25}$ (i.e. the treatment group) and those that were not (i.e. the control group). We then identify two time periods: one before and one after the introduction of the Intreo processes; in this case, as mentioned in Section 2.1, 2011 and 2013 respectively. When we are examining the impact of Intreo reforms on the probability to exit the Live Register to employment, for example, we can define the DiD estimator by letting:

- $q_{0, \mathrm{~T}}=$ the percentage of jobseekers in the treatment offices that exited to employment in 2011 (i.e. pre-Intreo);

- $q_{1, \mathrm{~T}}=$ the percentage of jobseekers in the treatment offices that exited to employment in 2013 (i.e. after the introduction of Intreo);

- $q_{0, \mathrm{c}}=$ the percentage of jobseekers in the control offices that exited to employment in 2011 (i.e. pre-Intreo);

- $q_{1, c}=$ the percentage of jobseekers in the control offices that exited to employment in 2013 (i.e. after the introduction of Intreo).

Using the DiD methodology, we compare the difference between the change in rates of exit to employment in each group before and after the introduction of the Intreo reforms. For the treatment group, the total difference in exit to employment rates before and after the introduction of the Intreo approach is $q_{1, \mathrm{~T}}-q_{0, \mathrm{~T}}$. For the non-Intreo control group, the total difference is $q_{1, c}-q_{0, c}$. The DiD equation is therefore expressed as:

$$
\operatorname{DiD}=\left(q_{1, \mathrm{~T}}-q_{0, \mathrm{~T}}\right)-\left(q_{1, \mathrm{c}}-q_{0, \mathrm{c}}\right)
$$

By making some reasonable assumptions, we should be able to predict the sign of this equation. If the introduction of the Intreo reforms increased the probability of claimants exiting from the Live Register to employment, then $\left(q_{1, \mathrm{~T}}-q_{0, \mathrm{~T}}\right)$ will be positive. The introduction of Intreo should have no impact on the outcomes of the control groups, so that, all else being equal, $\left(q_{1, c}-q_{0, c}\right)$ should be zero. Crucially, there should be no factor other than Intreo that affects the probability of exit of one group more than it affects the other. Therefore, if the Intreo process reforms increased the probability of exit to employment, the DiD coefficient will be positive. Each of the other outcomes that we examine the effect of the Intreo reforms on (i.e. exiting the Live Register, exiting to an education, training or employment placement course, or exiting to 'other') is undertaken using this same methodology.

The model to be estimated, which is applied to pooled (2011 and 2013) data, can 
be written as follows:

$$
Y_{i}=\hat{\alpha}_{0 i}+\hat{\beta}_{1} T_{i}+\hat{\beta}_{2} G_{i}+\hat{\beta}_{3}\left(T_{i} * G_{i}\right)+\hat{\beta}_{4} X_{i}+\widehat{\varepsilon}_{i t}
$$

where $Y_{i}$ is the progression outcome being examined (e.g. exit to employment) for person ' $i$ '; $\hat{\alpha}_{0 i}$ is the intercept term; $\hat{\beta}_{1}$ captures the time effect from moving from the pre-Intreo year to the post-Intreo year; $\hat{\beta}_{2}$ captures the group effect in the preIntreo year (i.e. any differences between the treatment and control groups in 2011); $\hat{\beta}_{3}$ is the DiD estimate, which captures the effect of the Intreo reforms on the outcome variable (e.g. exit to employment); $\hat{\beta}_{4}$ captures the impact of control variables used in the model; and $\hat{\varepsilon}_{i t}$ is the error term.

While technically rather straightforward, the DiD approach is extremely powerful as it eliminates any biases relating to time-invariant unobserved influences (i.e. unobserved heterogeneity). In terms of estimation, the DiD model is estimated using standard ordinary least squares (OLS) regression.

The DiD methodology provides an unbiased estimate of the impact of Intreo reforms if the trend over time would have been the same between the treatment and control groups in the absence of the intervention; this is what is known as the common trend assumption. For example, we should observe that the trend in outcomes between the two groups in previous years (prior to Intreo) was the same. If we then observe a deviation in this common trend after the introduction of Intreo, we can infer that this was due to the Intreo reforms.

This assumption can be tested using identical information about the treatment and control groups over a period where no intervention took place, also known as a placebo time period. In order to test that this common trend assumption holds for this evaluation of the Intreo reforms, the DEASP provided us with the required data for 2009. With these data, we were able to rerun the DiD model using information from 2009 as the placebo control period, and we used the 2011 information as the placebo treatment period. If common trends exist, the DiD coefficient in the placebo time period equation (i.e. 2009), $\hat{\beta}_{3}^{p l}$, should be equal to zero. If $\hat{\beta}_{3}^{p l}$ is statistically different from zero, this may indicate that the DiD framework is unsuitable to isolate the impact of Intreo.

A potential source of bias in a DiD model occurs when (i) treatment and control group composition changes over time - for example, the proportion of individuals in the treatment offices with third-level education falls over the two time periods being examined and that of individuals with low levels of education increases; or (ii) treatment and control groups differ on characteristics that are related to the trend over time. Propensity score matching (PSM) methods are commonly used to minimise this type of selection bias. Propensity scores, as proposed by Rosenbaum and Rubin (1983), are used to place a higher weight on the control group 
observations that have a similar set of observable characteristics to those in the treatment group, thereby comparing the outcomes of the treated with the outcomes of 'similar' individuals in the control group.

PSM methods are commonly used with a single treatment group and a single control group, whereby the propensity weights are applied to the control group to match their characteristics to those of the treatment group. In the DID framework, however, we have four different groups of interest: treatment group pre-Intreo (group 1), treatment group post-Intreo (group 2), control group pre-Intreo (group 3) and control group post-Intreo (group 4).

Stuart et al. (2014) proposed a methodology that applies the PSM strategy in the DiD framework. The strategy they suggested removes biases due to differences in covariate distributions between the four groups. In this setting, the propensity score is defined as the probability of being in the treatment group in the control period, versus the probability of being in each of the other three groups. To estimate the propensity scores, a multinomial logistic regression predicts the likelihood of being in each group as a function of a set of observed covariates $X_{i}$. For each individual $i$, a propensity score $e k\left(X_{i}\right)$, is estimated indicating the probability of being in group $k$, for $k=1-4$. These four probabilities sum to one for each individual. A set of propensity score weights is then created so that each group is weighted to be similar to the treatment group in the control period as follows:

$$
w_{i}=e_{1}\left(X_{i}\right) / e_{g}\left(X_{i}\right)
$$

where $g$ refers to the group in which individual $i$ is observed. Individuals in the treatment group in the control period receive a weight of 1 , while individuals in other groups receive a weight that captures the probability of being in group 1 relative to the probability of being in the group in which they were observed. Using these weights when estimating the DiD equation allows us to obtain a consistent estimate of the treatment effect of interest, even in the presence of selection on observed covariates across the four groups. ${ }^{26}$ We refer to this methodology as the PSM-DiD method. 


\section{CHAPTER 4}

\section{Descriptive statistics}

In this chapter we present descriptive statistics relating to a number of personal and unemployment characteristics for the treatment and control groups in both the control and treatment time periods, 2011 and 2013 respectively. As mentioned in Chapter 3, the treatment group consists of individuals from SWLOs that implemented the Intreo activation process reforms in 2012, whereas the control group are from offices that did not implement the Intreo PES reforms during the time period covered by the study. ${ }^{27}$ The control and treatment time periods are 2011 and 2013 and are denoted $T_{0}$ and $T_{1}$ respectively.

Table 4.1 presents descriptive statistics relating to the average characteristics of individuals in the treatment and control groups in both the control (2011) and treatment (2013) time periods. ${ }^{28}$ With regard to gender, 50-55 per cent of the sample in both treatment and control groups were males. The majority of individuals were single and a relatively high percentage were previously employed in elementary, clerical, sales or skilled trade occupations.

Taken as a whole, the data indicate that there were no large systematic differences between the control and treatment groups over the two time periods, indicating that problems related to potential selection bias are unlikely to impact our econometric estimates (Chapter 5 ). While most occupations are generally stable over time, there is a notable increase in elementary workers in the treatment group, from 15.7 per cent in 2011 to 24.2 per cent in 2013. Elementary workers in the control group, however, remained relatively unchanged over the two time periods (15.0 per cent in 2011 compared to 16.2 per cent in 2013). There was a 4 percentage point reduction in skilled trade workers between 2011 and 2013, in both treatment and control groups.

27 The Intreo reforms were not introduced in the control offices until at least 2014. As discussed in Chapter 3, 2014 was a minimum time period requirement in the selection of the control offices in order to avoid potential spill-over effects, i.e. individuals in the control offices receiving Intreo process reforms during the period of the study, thus potentially contaminating the evaluation results. Consequently, the Department ensured that the offices that were selected for the control group met this minimum Intreo introduction time period requirement.

28 Tables $\mathrm{A} 1$ and $\mathrm{A} 2$ in the appendix show the $p$-values for the differences between the treatment and control groups in each time period, as well as differences within the treatment and control groups across time. 


\begin{tabular}{|c|c|c|c|c|}
\hline & \multicolumn{2}{|c|}{ Treatment group } & \multicolumn{2}{|c|}{ Control group } \\
\hline & $\begin{array}{c}T=0 \\
(2011)\end{array}$ & $\begin{array}{c}T=1 \\
(2013)\end{array}$ & $\begin{array}{c}T=0 \\
(2011)\end{array}$ & $\begin{array}{c}T=1 \\
(2013)\end{array}$ \\
\hline Male & $53.8 \%$ & $50.0 \%$ & $55.0 \%$ & $49.5 \%$ \\
\hline Age (years) & 32.4 & 32.6 & 32.1 & 33.3 \\
\hline Irish national & $78.2 \%$ & $76.3 \%$ & $80.0 \%$ & $80.0 \%$ \\
\hline $\begin{array}{l}\text { Average number of dependent children (including no } \\
\text { children) }\end{array}$ & 0.25 & 0.28 & 0.25 & 0.27 \\
\hline \multicolumn{5}{|l|}{ Marital status } \\
\hline Married & $30.8 \%$ & $29.9 \%$ & $33.7 \%$ & $31.8 \%$ \\
\hline Cohabiting & $6.1 \%$ & $4.6 \%$ & $5.4 \%$ & $5.0 \%$ \\
\hline Separated & $4.4 \%$ & $5.2 \%$ & $4.0 \%$ & $4.6 \%$ \\
\hline Single & $57.1 \%$ & $58.9 \%$ & $55.7 \%$ & $57.5 \%$ \\
\hline Widow & $1.1 \%$ & $0.5 \%$ & $1.0 \%$ & $0.6 \%$ \\
\hline Unknown & $0.5 \%$ & $0.9 \%$ & $0.3 \%$ & $0.5 \%$ \\
\hline \multicolumn{5}{|l|}{ Occupation } \\
\hline Managers & $7.0 \%$ & $9.4 \%$ & $7.4 \%$ & $9.7 \%$ \\
\hline Professionals & $8.2 \%$ & $7.6 \%$ & $11.5 \%$ & $12.5 \%$ \\
\hline Associate professionals & $5.2 \%$ & $5.5 \%$ & $5.1 \%$ & $5.4 \%$ \\
\hline Clerical & $13.9 \%$ & $11.0 \%$ & $9.7 \%$ & $9.0 \%$ \\
\hline Skilled trades & $15.0 \%$ & $10.7 \%$ & $14.0 \%$ & $10.1 \%$ \\
\hline Other services & $12.2 \%$ & $11.0 \%$ & $10.6 \%$ & $12.1 \%$ \\
\hline Sales & $13.1 \%$ & $11.5 \%$ & $16.6 \%$ & $14.4 \%$ \\
\hline Operatives & $9.8 \%$ & $9.1 \%$ & $10.0 \%$ & $10.7 \%$ \\
\hline Elementary & $15.7 \%$ & $24.2 \%$ & $15.0 \%$ & $16.2 \%$ \\
\hline Observations & $n=4478$ & $n=3936$ & $n=5320$ & $n=3968$ \\
\hline
\end{tabular}

Source: JLD.

Table 4.2 gives information on the earnings of the claimants' spouses. This category is not applicable for the majority of individuals: this is consistent with the descriptive statistics from Table 4.1, which show that approximately 60 per cent of individuals are single. Of the applicable categories, most have a spouse with zero earnings (approximately 14 per cent in the treatment and control groups). 


\begin{tabular}{|c|c|c|c|c|}
\hline & \multicolumn{2}{|c|}{ Treatment group } & \multicolumn{2}{|c|}{ Control group } \\
\hline & $T=0(2011)$ & $T=1(2013)$ & $T=0(2011)$ & $T=1(2013)$ \\
\hline $\mathrm{Nil}$ & $14.0 \%$ & $12.9 \%$ & $14.0 \%$ & $13.2 \%$ \\
\hline Not applicable & $67.1 \%$ & $67.0 \%$ & $66.0 \%$ & $64.6 \%$ \\
\hline$<€ 100$ & $0.1 \%$ & $0.1 \%$ & $0.1 \%$ & $0.2 \%$ \\
\hline$€ 100-€ 310$ & $1.0 \%$ & $0.6 \%$ & $0.8 \%$ & $0.8 \%$ \\
\hline$€ 310-€ 400$ & $1.6 \%$ & $1.5 \%$ & $1.9 \%$ & $1.5 \%$ \\
\hline$€ 400+$ & $10.3 \%$ & $10.5 \%$ & $10.7 \%$ & $13.6 \%$ \\
\hline Details unknown & $6.0 \%$ & $7.4 \%$ & $6.5 \%$ & $6.2 \%$ \\
\hline Observations & $n=4478$ & $n=3936$ & $n=5320$ & $n=3968$ \\
\hline
\end{tabular}

Source: JLD.

Table 4.3 provides information on claimants' employment history prior to becoming unemployed. Again, the data indicate that there were no large systematic differences between the control and treatment groups over the two time periods (2011 and 2013).

\section{TABLE 4.3 CLAIMANTS' EMPLOYMENT HISTORY PRIOR TO BECOMING UNEMPLOYED}

\begin{tabular}{|c|c|c|c|c|}
\hline & \multicolumn{2}{|c|}{ Treatment group } & \multicolumn{2}{|c|}{ Control group } \\
\hline & $\begin{array}{c}T=0 \\
(2011)\end{array}$ & $\begin{array}{c}T=1 \\
(2013)\end{array}$ & $\begin{array}{c}T=0 \\
(2011)\end{array}$ & $\begin{array}{c}T=1 \\
(2013)\end{array}$ \\
\hline $\begin{array}{l}\text { Number of employment episodes prior to becoming } \\
\text { unemployed }\end{array}$ & 1.8 & 1.7 & 2.1 & 2.0 \\
\hline $\begin{array}{l}\text { Duration of employment episodes (days) prior to } \\
\text { becoming unemployed }\end{array}$ & 1941 & 1950 & 2056 & 2219 \\
\hline Observations & $n=4478$ & $n=3936$ & $n=5320$ & $n=3968$ \\
\hline
\end{tabular}

Source: JLD

Table 4.4 provides descriptive statistics on the percentage of treatment and control group claimants in employment at three, six, nine and 12 months after their first claim. In both the treatment and control groups, there is a slight increase in the percentage in employment in 2013 compared to 2011. The magnitude of the increase is similar in both groups and therefore there is no clear descriptive evidence of a significant effect of the Intreo activation process reforms on the probability of claimants exiting the Live Register to employment. 


\begin{tabular}{|l|c|c|c|c|}
\hline & \multicolumn{2}{|c|}{ Treatment group } & \multicolumn{2}{c|}{ Control group } \\
\hline & $\boldsymbol{T = 0 ( 2 0 1 1 )}$ & $\boldsymbol{T = 1 ( 2 0 1 3 )}$ & $\boldsymbol{T = 0}$ (2011) & $\boldsymbol{T}=\mathbf{1}$ (2013) \\
\hline In employment 3 months after event & $14.6 \%$ & $18.7 \%$ & $18.6 \%$ & $21.0 \%$ \\
\hline In employment 6 months after event & $26.4 \%$ & $30.0 \%$ & $31.6 \%$ & $33.9 \%$ \\
\hline In employment 9 months after event & $31.4 \%$ & $35.1 \%$ & $37.2 \%$ & $39.7 \%$ \\
\hline $\begin{array}{l}\text { In employment 12 months after } \\
\text { event }\end{array}$ & $34.3 \%$ & $37.3 \%$ & $39.9 \%$ & $42.9 \%$ \\
\hline Observations & $n=4478$ & $n=3936$ & $n=5320$ & $n=3968$ \\
\hline
\end{tabular}

Source: JLD.

Tables 4.5 and 4.6 provide descriptive statistics relating to the other outcome categories: the percentages exiting to education or training, and the percentages exiting the Live Register for 'other' reasons. Approximately 1.5 to 2 per cent of claimants go into education or training at the three-month interval, increasing to between 5 and 8 per cent in subsequent periods following the start of their claim. Individuals closing off the Live Register for 'other' reasons, such as being transferred to another DEASP scheme or no longer being entitled to JB, account for approximately 2 per cent of claimants after three months, with this figure increasing to between 10 and 13 per cent after 12 months.

TABLE 4.5

PERCENTAGES IN EDUCATION OR TRAINING: 3, 6, 9 AND 12 MONTHS AFTER FIRST CLAIM

\begin{tabular}{|c|c|c|c|c|}
\hline & \multicolumn{2}{|c|}{ Treatment Group } & \multicolumn{2}{|c|}{ Control Group } \\
\hline & $T=0(2011)$ & $T=1(2013)$ & $T=0$ (2011) & $T=1(2013)$ \\
\hline $\begin{array}{l}\text { Education/training } 3 \text { months after } \\
\text { event }\end{array}$ & $1.6 \%$ & $2.3 \%$ & $1.5 \%$ & $2.0 \%$ \\
\hline $\begin{array}{l}\text { Education/training } 6 \text { months after } \\
\text { event }\end{array}$ & $5.3 \%$ & $6.8 \%$ & $5.4 \%$ & $6.5 \%$ \\
\hline $\begin{array}{l}\text { Education/training } 9 \text { months after } \\
\text { event }\end{array}$ & $7.1 \%$ & $8.9 \%$ & $7.5 \%$ & $9.3 \%$ \\
\hline $\begin{array}{l}\text { Education/training } 12 \text { months after } \\
\text { event }\end{array}$ & $6.7 \%$ & $7.6 \%$ & $6.8 \%$ & $8.0 \%$ \\
\hline Observations & $n=4478$ & $n=3936$ & $n=5320$ & $n=3968$ \\
\hline
\end{tabular}




\begin{tabular}{|l|c|c|c|c|}
\hline & \multicolumn{2}{|c|}{ Treatment Group } & \multicolumn{2}{c|}{ Control Group } \\
\hline & $\boldsymbol{T = 0 ( 2 0 1 1 )}$ & $\boldsymbol{T = 1 ( 2 0 1 3 )}$ & $\boldsymbol{T}=\mathbf{0}(\mathbf{2 0 1 1})$ & $\boldsymbol{T}=\mathbf{1}(\mathbf{2 0 1 3 )}$ \\
\hline Other reasons 3 months after event & $1.6 \%$ & $2.8 \%$ & $1.8 \%$ & $1.5 \%$ \\
\hline Other reasons 6 months after event & $5.4 \%$ & $6.5 \%$ & $5.3 \%$ & $4.7 \%$ \\
\hline Other reasons 9 months after event & $7.8 \%$ & $9.6 \%$ & $7.2 \%$ & $7.8 \%$ \\
\hline Other reasons 12 months after event & $11.0 \%$ & $13.3 \%$ & $10.0 \%$ & $11.0 \%$ \\
\hline Observations & $n=4478$ & $n=3936$ & $n=5320$ & $n=3968$ \\
\hline
\end{tabular}

Source: JLD 


\section{CHAPTER 5}

\section{Econometric results}

In this chapter, we present and discuss the results of the econometric analysis of the effectiveness of the Intreo activation process reforms to Ireland's PES. We begin by examining the impact of the Intreo reforms on the probability of a jobseeker having exited the Live Register. We then examine the impact of the new Intreo PES model on the probability of a claimant being: (i) in employment, (ii) in education or training or on an employment placement course, and (iii) in an 'other' Live Register exit category.

In each case, we examine the probability of being in the relevant outcome category at three months, six months, nine months and 12 months after the first interaction with an Intreo centre. All results are estimated using the PSM-DiD framework, where the weights are estimated using the methods described in Chapter $3 .{ }^{29}$

\subsection{CLOSED OFF THE LIVE REGISTER}

Table 5.1 presents PSM-DiD estimates of the impact of the Intreo activation process reforms on the probability of a claimant having exited the Live Register three months, six months, nine months and 12 months after their first interaction with the new Intreo PES model. In each case, the coefficients show the impact of a marginal increase in the variable of interest on the probability of having exited the Live Register at each of the time points considered. ${ }^{30}$ Note that a person may exit the Live Register for various reasons: finding a job, going into education or for other reasons. In this section, we begin by looking at whether a person has exited the Live Register and in the sections that follow this we examine the specific type of Live Register exits (employment, etc.).

The coefficients associated with our independent variables reveal that those with an earning spouse, married individuals and those who were recently in higher skilled occupations are more likely to have exited the Live Register. In addition, the greater the number of employment episodes that an individual had prior to becoming unemployed, the more likely they will be to have left the Live Register. However, as the number of dependent children increases, the probability of exiting the Live Register decreases. In addition, being Irish, relative to all other

29 Propensity scores are estimated based on the following variables: sex, age, spousal income, number of dependent children, jobseekers claim in past 30 days, nationality (Irish), marital status, claim type, occupation, number of previous employment episodes, previous employment duration, and a dummy variable indicating receipt of pre-Intreo training (BTEA, FÁS, etc.). Appendix Table A3 compares the unweighted and weighted summary statistics.

30 For categorical explanatory variables (e.g. male), the coefficient shows the probability of exiting the Live Register relative to the omitted category (in the example given, female). 
nationalities, is associated with a lower probability of exiting the Live Register. We also include a dummy variable to indicate whether the individual received preIntreo training, which primarily relates to pre-Intreo Community Employment (CE) schemes or FAS events. Given that our sample conditions on individuals with no Live Register history, we would not expect to observe many of these cases. However, it should be noted that for programmes such as the CE scheme, individuals could qualify without being in receipt of JA or JB. ${ }^{31}$ Approximately 7 per cent of the sample have pre-Intreo training. According to the results in Table 5.1, having pre-Intreo training reduces a person's probability of exiting the Live Register by between 2 and 7 percentage points. ${ }^{32}$

The coefficient of primary interest is the DiD coefficient $\left(T_{i}^{*} G_{i}\right)$, which shows the impact of the introduction of the Intreo activation process reforms on the probability of having exited the Live Register at each of the time points examined. The results suggest that the Intreo reforms had a small but statistically significant positive impact on the probability of having exited the Live Register at three months, six months and nine months after the individual's first interaction with an Intreo centre. After three months, individuals in Intreo offices were 3.4 percentage points more likely to have exited the Live Register than those in the control offices, controlling for a range of confounding variables. After six and nine months the effect was 4.0 percentage points and 3.1 percentage points respectively. After 12 months, however, there was no statistically significant difference in the probability of having exited the Live Register between individuals in Intreo offices and individuals in the control SWLOs that operated under the NEAP PES model. Nevertheless, the activation reforms introduced to Ireland's PES under Intreo do appear to be effective in reducing the incidence of short-run durations on the Live Register. From a budget perspective, this reduction in durations is likely to have an impact on the Exchequer costs of payments to jobseekers.

31 For example, individuals can qualify through the One-Parent Family scheme.

32 We cannot rule out administrative errors in the data whereby some of these individuals actually were previously on the Live Register but were not classified as such. However, we observe the same results even if we exclude the preIntreo training individuals from our sample (results available from the authors on request). 
TABLE 5.1 PSM-DID RESULTS FOR PROBABILITY OF EXITING THE LIVE REGISTER

\begin{tabular}{|c|c|c|c|c|}
\hline & $\begin{array}{c}3 \\
\text { months }\end{array}$ & $\begin{array}{c}6 \\
\text { months }\end{array}$ & $\begin{array}{c}9 \\
\text { months }\end{array}$ & $\begin{array}{c}12 \\
\text { months }\end{array}$ \\
\hline \multirow[t]{2}{*}{ Treatment group $\left(G_{i}\right)$} & $-0.032^{* * *}$ & $-0.029 * * *$ & $-0.035 * * *$ & $-0.036 * * *$ \\
\hline & (0.009) & (0.011) & (0.011) & (0.011) \\
\hline \multirow[t]{2}{*}{$2013\left(T_{i}\right)$} & $0.031 * * *$ & $0.035^{* * *}$ & $0.060 * * *$ & $0.055^{* * *}$ \\
\hline & (0.009) & $(0.010)$ & (0.010) & (0.010) \\
\hline \multirow[t]{2}{*}{$\operatorname{DiD}\left(T_{i}^{*} G_{i}\right)$} & $0.034 * * *$ & $0.040 * * *$ & $0.031^{* *}$ & 0.021 \\
\hline & $(0.012)$ & (0.014) & (0.015) & (0.014) \\
\hline \multirow[t]{2}{*}{ Male } & 0.005 & 0.009 & 0.010 & -0.005 \\
\hline & $(0.007)$ & $(0.008)$ & $(0.008)$ & $(0.008)$ \\
\hline \multirow[t]{2}{*}{ Age at start of event } & $0.008^{* * *}$ & $0.005^{* *}$ & $0.006 * * *$ & $0.005^{* *}$ \\
\hline & $(0.002)$ & $(0.002)$ & $(0.002)$ & $(0.002)$ \\
\hline \multirow[t]{2}{*}{ Age squared } & $-0.000 * * *$ & $-0.000 * * *$ & $-0.000 * * *$ & $-0.000 * * *$ \\
\hline & $(0.000)$ & $(0.000)$ & $(0.000)$ & $(0.000)$ \\
\hline \multicolumn{5}{|l|}{$\begin{array}{l}\text { Spousal earnings ( } € \text { p.w., relative to zero } \\
\text { spousal earnings) }\end{array}$} \\
\hline \multirow[t]{2}{*}{ Not applicable } & $0.035^{* * *}$ & $0.049 * * *$ & $0.040^{* *}$ & $0.063 * * *$ \\
\hline & (0.013) & (0.016) & (0.016) & (0.016) \\
\hline \multirow[t]{2}{*}{$<€ 100.00$} & 0.030 & $0.365^{* * *}$ & $0.304^{* * *}$ & $0.323 * * *$ \\
\hline & (0.089) & $(0.107)$ & (0.108) & $(0.107)$ \\
\hline \multirow[t]{2}{*}{$€ 100-310.00$} & $0.107^{* * *}$ & $0.219 * * *$ & $0.220 * * *$ & $0.235^{* * *}$ \\
\hline & $(0.031)$ & $(0.037)$ & $(0.037)$ & $(0.037)$ \\
\hline \multirow[t]{2}{*}{$€ 310.01-€ 400.00$} & $0.074 * * *$ & $0.083 * * *$ & $0.132 * * *$ & $0.144 * * *$ \\
\hline & $(0.025)$ & $(0.030)$ & $(0.030)$ & $(0.030)$ \\
\hline \multirow[t]{2}{*}{$\geq € 401.00$} & $0.046^{* * *}$ & $0.043^{* * *}$ & $0.059 * * *$ & $0.133^{* * *}$ \\
\hline & $(0.014)$ & $(0.017)$ & $(0.017)$ & $(0.017)$ \\
\hline \multirow[t]{2}{*}{ Details unknown } & $-0.039 * * *$ & $-0.072^{* * *}$ & $-0.105^{* * *}$ & $-0.066^{* * *}$ \\
\hline & $(0.015)$ & (0.018) & (0.018) & (0.018) \\
\hline \multirow[t]{2}{*}{ No. child dependants } & $-0.018^{* * *}$ & $-0.026^{* * *}$ & $-0.029 * * *$ & $-0.032 * * *$ \\
\hline & $(0.004)$ & $(0.004)$ & $(0.004)$ & $(0.004)$ \\
\hline \multirow[t]{2}{*}{ Irish (relative to all other nationalities) } & $-0.022^{* * *}$ & $-0.029 * * *$ & $-0.048 * * *$ & $-0.059 * * *$ \\
\hline & $(0.008)$ & $(0.010)$ & $(0.010)$ & $(0.010)$ \\
\hline \multicolumn{5}{|l|}{ Marital status (relative to married) } \\
\hline \multirow[t]{2}{*}{ Cohabiting } & -0.015 & $-0.058 * * *$ & $-0.053 * * *$ & $-0.068^{* * *}$ \\
\hline & $(0.014)$ & $(0.017)$ & $(0.017)$ & $(0.017)$ \\
\hline \multirow[t]{2}{*}{ Separated } & $-0.054 * * *$ & $-0.099 * * *$ & $-0.104 * * *$ & $-0.125^{* * *}$ \\
\hline & $(0.017)$ & $(0.021)$ & $(0.021)$ & $(0.021)$ \\
\hline \multirow[t]{2}{*}{ Single } & $-0.035^{* * *}$ & $-0.024^{*}$ & -0.007 & -0.020 \\
\hline & $(0.011)$ & $(0.013)$ & $(0.013)$ & $(0.013)$ \\
\hline \multirow[t]{2}{*}{ Widow } & -0.046 & $-0.065^{*}$ & 0.006 & -0.004 \\
\hline & $(0.030)$ & $(0.036)$ & $(0.036)$ & $(0.036)$ \\
\hline \multirow[t]{2}{*}{ Unknown } & 0.033 & -0.024 & -0.036 & -0.041 \\
\hline & $(0.042)$ & $(0.049)$ & $(0.050)$ & $(0.050)$ \\
\hline \multirow[t]{2}{*}{ JB claim category (relative to JA) } & $-0.185^{* * *}$ & -0.019 & $0.075^{* * *}$ & $0.107^{* * *}$ \\
\hline & $(0.015)$ & $(0.018)$ & (0.019) & $(0.018)$ \\
\hline \multicolumn{5}{|l|}{ Occupation (relative to elementary) } \\
\hline Manager & $0.062 * * *$ & $0.098 * * *$ & $0.088 * * *$ & $0.123 * * *$ \\
\hline
\end{tabular}




\begin{tabular}{|c|c|c|c|c|}
\hline & $\begin{array}{c}3 \\
\text { months }\end{array}$ & $\begin{array}{c}6 \\
\text { months }\end{array}$ & $\begin{array}{c}9 \\
\text { months }\end{array}$ & $\begin{array}{c}12 \\
\text { months }\end{array}$ \\
\hline & $(0.015)$ & (0.018) & (0.018) & $(0.018)$ \\
\hline \multirow[t]{2}{*}{ Professional } & $0.107 * * *$ & $0.159 * * *$ & $0.162 * * *$ & $0.173 * * *$ \\
\hline & $(0.014)$ & $(0.016)$ & (0.017) & $(0.017)$ \\
\hline \multirow[t]{2}{*}{ Associate professional } & $0.067 * * *$ & $0.113^{* * *}$ & $0.108 * * *$ & $0.123 * * *$ \\
\hline & $(0.016)$ & $(0.019)$ & (0.019) & (0.019) \\
\hline \multirow[t]{2}{*}{ Clerical } & $0.076 * * *$ & $0.093 * * *$ & $0.093 * * *$ & $0.108 * * *$ \\
\hline & $(0.012)$ & $(0.014)$ & $(0.015)$ & $(0.014)$ \\
\hline \multirow[t]{2}{*}{ Skilled trades } & $0.045^{* * *}$ & $0.029 * *$ & 0.021 & $0.035^{* *}$ \\
\hline & $(0.012)$ & $(0.014)$ & $(0.014)$ & $(0.014)$ \\
\hline \multirow[t]{2}{*}{ Other services } & $0.028 * *$ & $0.051 * * *$ & $0.043 * * *$ & $0.040 * * *$ \\
\hline & $(0.012)$ & $(0.014)$ & $(0.014)$ & $(0.014)$ \\
\hline \multirow[t]{2}{*}{ Sales } & $0.028 * *$ & $0.060 * * *$ & $0.069 * * *$ & $0.079 * * *$ \\
\hline & $(0.012)$ & $(0.014)$ & $(0.014)$ & $(0.014)$ \\
\hline \multirow[t]{2}{*}{ Operatives } & $0.040 * * *$ & $0.045^{* * *}$ & $0.034 * *$ & $0.055 * * *$ \\
\hline & $(0.013)$ & $(0.015)$ & $(0.015)$ & $(0.015)$ \\
\hline \multirow[t]{2}{*}{ Number of pre-event employment events } & $0.023 * * *$ & $0.031 * * *$ & $0.034 * * *$ & $0.033 * * *$ \\
\hline & $(0.002)$ & $(0.002)$ & $(0.002)$ & $(0.002)$ \\
\hline \multirow[t]{2}{*}{$\begin{array}{l}\text { Total duration of pre-event employment ev } \\
\text { (calendar days) }\end{array}$} & $0.000^{*}$ & -0.000 & $0.000 * *$ & $0.000 * * *$ \\
\hline & $(0.000)$ & $(0.000)$ & $(0.000)$ & $(0.000)$ \\
\hline \multirow[t]{2}{*}{ Pre-Intreo training } & $-0.021^{*}$ & $-0.057^{* * *}$ & $-0.075^{* * *}$ & $-0.046^{* * *}$ \\
\hline & $(0.011)$ & $(0.013)$ & $(0.013)$ & $(0.013)$ \\
\hline \multirow[t]{2}{*}{ Unemployment rate } & -0.003 & 0.001 & 0.002 & -0.001 \\
\hline & $(0.002)$ & $(0.003)$ & $(0.003)$ & $(0.003)$ \\
\hline \multirow[t]{2}{*}{ Constant } & $0.095^{*}$ & $0.271 * * *$ & $0.345^{* * *}$ & $0.436 * * *$ \\
\hline & (0.049) & $(0.059)$ & (0.059) & (0.059) \\
\hline Observations & 17,499 & 17,321 & 17,263 & 17,233 \\
\hline$R$-squared & 0.050 & 0.071 & 0.089 & 0.091 \\
\hline
\end{tabular}

Source: Authors' estimates.

As discussed in Chapter 3, a key assumption of the DiD framework is that common trends exist between treatment and control groups. One way to see this would be to plot the outcome variables for the treatment and control groups over time; specifically, prior to the introduction of the Intreo activation process reforms in 2012.

To test this common trends assumption, the DEASP provided us with 2009 data, in addition to the 2011 and 2013 data. Using these data, we tested the assumption of common trends by estimating our PSM-DiD model on a placebo time period in which no Intreo activation process reforms were implemented, namely 2009 and 2011. The presence of a statistically significant DiD coefficient in the placebo model would call into question the common trends assumption and therefore the reliability of the results obtained for the non-placebo years. 
In Table 5.2, we show the results from our placebo test. The top row of the table shows the DiD coefficients from a PSM-DID analysis run over the placebo time period (2009-2011). All control variables are included in all regression models, though all are not shown for brevity. ${ }^{33}$ In each case, the DiD coefficient is statistically significantly different from zero, indicating that common trends do not exist between treatment and control groups, at least for the period 2009-2011. This calls into question the reliability of the DiD coefficients from the main analysis for 2011-2013. However, the DiD coefficient for the placebo years is negative, which indicates that over the period 2009 to 2011 the rate of exits from the Live Register was higher in the control offices. If this relationship was constant over time, and would have also been present in the absence of any treatment in the 2011 to 2013 period, this would imply that the model could be exerting a downward bias that is resulting in a possible underestimation of the Intreo activation process reform impacts. ${ }^{34}$

The presence of statistically significant pre-treatment effects for the placebo years is an indication that the control offices are not a valid counterfactual for the treatment offices. The key assumption for a valid counterfactual in the DiD analysis is that in the absence of the Intreo PES reforms the treatment offices would have displayed the same outcome trends as the control offices. However, the placebo analysis showed this was not the case in the preceding years. The reason for this may be some systematic difference between the treatment and control offices.

One clear difference between treatment and control offices relates to their geographical location. Four of the seven treatment offices are located in Dublin, and one is close to Dublin (Bray, Co. Wicklow). The control offices are primarily located along the western seaboard: there are two control offices in Cork and one each in Galway, Mayo, Donegal and Tipperary. There is just one control office in Dublin. In our econometric set-up, we included local unemployment rates to try to control for regional variation in labour markets throughout the country. However, it is likely that other geographic differences exist that are not fully captured by the local unemployment rate. Such differences could potentially invalidate the assumption that the control offices represent a valid counterfactual for the treatment offices.

In order to try to address this issue, we estimate two separate models using group treatment and control offices which are located in similar geographical locations. In the first model, our treatment offices are in Donegal (Buncrana) and Sligo and the control offices are in Donegal (Letterkenny) and Mayo (Westport). The second model uses two Dublin offices as the treatment and control offices (Tallaght and Nutgrove). It should be noted that while this approach may reduce observable differences between the control and treatment offices, the estimates are highly 
location-specific and, as such, may not necessarily reflect the impact of the Intreo activation process reforms nationally.

The lower panels of Table 5.2 use the same PSM-DiD framework to evaluate the impact of the Intreo PES reforms using only the aforementioned treatment and control offices. In the Nutgrove-Tallaght model, there is evidence of a 10 percentage point increase in the probability of exiting the Live Register between nine and 12 months following the individual's initial claim. A negative, statistically significant result is found in the placebo year for this model at the nine-month interval. There is no statistically significant effect for the Buncrana-LetterkennySligo-Westport model. The results of the geographical sub-models provide some indication that the Intreo reforms resulted in some acceleration of exits from the Live Register, at least in the Dublin region.

In the following sections, we examine the various outcome categories in more detail (e.g. exits to employment) in order to examine the extent to which any increase in the probability of exiting the Live Register is a result of Intreo activation process reforms.

TABLE 5.2 DID COEFFICIENTS FROM PSM-DID ANALYSIS OF PROBABILITY OF EXITING THE LIVE REGISTER

\begin{tabular}{|l|c|c|c|c|c|}
\hline & $\mathbf{3}$ months & $\mathbf{6}$ months & $\mathbf{9}$ months & $\mathbf{1 2}$ months \\
\hline All offices & & & & \\
\hline Placebo (2009-2011) & $-0.041^{* * *}$ & $-0.033^{* * *}$ & $-0.036^{* * *}$ & $-0.026^{* *}$ \\
\hline & $(0.009)$ & $(0.011)$ & $(0.011)$ & $(0.011)$ \\
\hline & $n=31,667$ & $n=31,363$ & $n=31,255$ & $n=31,193$ \\
\hline Main (2011-2013) & $0.034^{* * *}$ & $0.040^{* * *}$ & $0.031^{* *}$ & 0.021 \\
\hline & $(0.012)$ & $(0.014)$ & $(0.015)$ & $(0.014)$ \\
\hline Buncrana, Letterkenny, Sligo, Westport & $n=17,499$ & $n=17,321$ & $n=17,263$ & $n=17,233$ \\
\hline Placebo (2009-2011) & 0.021 & 0.004 & $0.058^{* *}$ & 0.026 \\
\hline & $(0.022)$ & $(0.027)$ & $(0.029)$ & $(0.029)$ \\
\hline Main (2011-2013) & $n=4,255$ & $n=4,206$ & $n=4,176$ & $n=4,165$ \\
\hline & 0.030 & 0.034 & -0.019 & -0.010 \\
\hline Nutgrove, Tallaght & $(0.032)$ & $(0.039)$ & $(0.041)$ & $(0.041)$ \\
\hline Placebo (2009-2011) & $n=2,239$ & $n=2,213$ & $n=2,196$ & $n=2,196$ \\
\hline & & & & \\
\hline & 0.025 & -0.029 & $-0.076 * * *$ & -0.037 \\
\hline Main (2011-2013) & $(0.019)$ & $(0.023)$ & $(0.023)$ & $(0.024)$ \\
\hline & $n=6,485$ & $n=6,443$ & $n=6,423$ & $n=6,414$ \\
\hline Source: Authors' estimates. & -0.034 & 0.016 & $0.107^{* * *}$ & $0.093^{* * *}$ \\
\hline & $(0.025)$ & $(0.030)$ & $(0.031)$ & $(0.031)$ \\
\hline & $n=3,858$ & $n=3,818$ & $n=3,814$ & $n=3,800$ \\
\hline & & & & \\
\hline & & & & \\
\hline
\end{tabular}

Source: Authors' estimates. 


\subsection{DETAILED OUTCOME CATEGORIES}

Table 5.3 examines the change in the probability of exiting the Live Register to employment at each time point (three, six, nine and 12 months) as a result of being exposed to Intreo activation process reforms. The results for the baseline model, which includes all treatment and control offices, indicate that Intreo had a positive and statistically significant effect on an individual's probability of finding employment three months after the start of their claim. The magnitude of the effect is in the order of 2 percentage points. However, as before, the baseline model does not pass the placebo test, which calls into question the validity of the common trends assumption. Nonetheless, as was the case in Table 5.2, the placebo coefficients are negative and this implies that the model could be exerting a downward bias that is resulting in a possible underestimation of the Intreo PES reform impacts.

If it could be established that the negative placebo effect was part of a trend of lower exit rates in the treatment offices prior to the introduction of the Intreo process reforms, then a movement from a negative to a neutral impact in 2013 could be interpreted as a positive treatment effect. However, there were insufficient data to validate the existence of differential trends between the treatment and control office exit rates prior to 2011.

There is some evidence of an employment effect at six months when we focus on the Buncrana, Letterkenny, Sligo and Westport offices, whereby individuals from Intreo offices were 7 percentage points more likely to be in employment. In the Nutgrove-Tallaght model, there is evidence of a positive employment effect of approximately 5 percentage points after 12 months. However, the results show a negative and significant employment effect after three months. While the Nutgrove-Tallaght model passes the placebo test, with no statistically significant results in the placebo years, the Buncrana-Letterkenny-Sligo-Westport model shows a positive and statistically significant employment result after three months, albeit the strength of the effect is very small.

In summary, while there is some weak evidence of a positive employment effect as a result of Intreo, particularly at the three- and six-month periods, the results do not establish a conclusive employment effect due to the presence of some significant placebo coefficients and the negative three-month coefficient for Nutgrove and Tallaght. Nonetheless, given the relatively short time period that has elapsed since the implementation of the Intreo activation process reforms in the treatment offices, the finding of any positive impacts on transitions to employment is promising, particularly considering that the Intreo reforms focused on streamlining the activation process as opposed to altering the form of interventions provided to jobseekers (i.e. no extensive changes in the ALMP provided under the Intreo PES from what was provided under the NEAP PES model). 
TABLE 5.3 PSM-DID ANALYSIS OF PROBABILITY OF BEING IN EMPLOYMENT

\begin{tabular}{|l|c|c|c|c|c|}
\hline & $\mathbf{3}$ months & $\mathbf{6}$ months & $\mathbf{9}$ months & $\mathbf{1 2}$ months \\
\hline All offices & & & & & \\
\hline & $-0.029 * * *$ & $-0.030 * * *$ & $-0.039 * * *$ & $-0.025 * *$ \\
\hline Placebo (2009-2011) & $(0.008)$ & $(0.010)$ & $(0.010)$ & $(0.010)$ \\
\hline & $n=31,667$ & $n=31,363$ & $n=31,255$ & $n=31,193$ \\
\hline Main (2011-2013) & $0.019 *$ & 0.018 & 0.015 & 0.004 \\
\hline & $(0.011)$ & $(0.013)$ & $(0.014)$ & $(0.014)$ \\
\hline Buncrana, Letterkenny, Sligo, Westport & $n=17,499$ & $n=17,321$ & $n=17,263$ & $n=17,233$ \\
\hline Placebo (2009-2011) & $0.033 *$ & -0.023 & -0.011 & -0.004 \\
\hline & $(0.020)$ & $(0.024)$ & $(0.025)$ & $(0.026)$ \\
\hline Main (2011-2013) & $n=4,255$ & $n=4,206$ & $n=4,176$ & $n=4,165$ \\
\hline & 0.012 & $0.070 * *$ & 0.050 & 0.028 \\
\hline Nutgrove, Tallaght & $(0.027)$ & $(0.033)$ & $(0.034)$ & $(0.035)$ \\
\hline Placebo (2009-2011) & $n=2,239$ & $n=2,213$ & $n=2,196$ & $n=2,196$ \\
\hline & & & & \\
\hline
\end{tabular}

Source: Authors' estimates

Table 5.4 examines the impact of Intreo PES process reforms on the probability of being in education or training or on an employment placement course for each time point. There is no evidence of any effect due to the Intreo reforms for the baseline model. Likewise, for the geographical sub-models, there is no conclusive evidence. While the results show a positive and significant effect for the NutgroveTallaght model at nine months, there is a negative effect of roughly the same magnitude for the Buncrana-Letterkenny-Sligo-Westport model. Furthermore, as with the other outcome categories shown above, the models show some significant results for the placebo years. 
TABLE 5.4 PSM-DID ANALYSIS OF PROBABILITY OF BEING IN EDUCATION, TRAINING OR EMPLOYMENT PLACEMENT COURSE

\begin{tabular}{|l|c|c|c|c|c|}
\hline & $\mathbf{3}$ months & $\mathbf{6}$ months & $\mathbf{9}$ months & $\mathbf{1 2}$ months \\
\hline All offices & & & & \\
\hline & -0.002 & 0.001 & 0.002 & -0.000 \\
\hline Placebo (2009-2011) & $(0.003)$ & $(0.004)$ & $(0.005)$ & $(0.005)$ \\
\hline & $n=31,667$ & $n=31,363$ & $n=31,255$ & $n=31,193$ \\
\hline Main (2011-2013) & -0.001 & 0.003 & -0.000 & -0.006 \\
\hline & $(0.004)$ & $(0.007)$ & $(0.008)$ & $(0.008)$ \\
\hline Buncrana, Letterkenny, Sligo, Westport & $n=17,499$ & $n=17,321$ & $n=17,263$ & $n=17,233$ \\
\hline Placebo (2009-2011) & 0.001 & $0.038 * * *$ & $0.040 * *$ & 0.023 \\
\hline & $(0.009)$ & $(0.014)$ & $(0.016)$ & $(0.016)$ \\
\hline Main (2011-2013) & $n=4,255$ & $n=4,206$ & $n=4,176$ & $n=4,165$ \\
\hline & 0.000 & $-0.048 *$ & -0.041 & -0.037 \\
\hline Nutgrove, Tallaght & $(0.014)$ & $(0.025)$ & $(0.028)$ & $(0.026)$ \\
\hline Placebo (2009-2011) & $n=2,239$ & $n=2,213$ & $n=2,196$ & $n=2,196$ \\
\hline & & & & \\
\hline
\end{tabular}

Source: Authors' estimates.

All individuals who are closed off the Liver Register at the time point of interest, but are not in employment, education or training or on an employment placement course, are categorised as being in the 'other' outcome category, a category that was devised by the Department in the data that it provided us with for this evaluation.

Table 5.5 shows there was a small but statistically significant increase in the probability of being in the 'other' category as a result of the Intreo activation process reforms across all time points. In the baseline model, which uses all offices, individuals exposed to the Intreo PES model are approximately 2 percentage points more likely to be in the 'other' outcome category than individuals in the control offices. The only significant result for the placebo years is a small, negative coefficient at the three-month period. While the Buncrana-Letterkenny-SligoWestport model shows no significant results, the Nutgrove-Tallaght model indicates, similarly to the baseline model, that individuals exposed to Intreo were 2-3 percentage points more likely to be in the 'other' category after three and six months. 


\begin{tabular}{|l|c|c|c|c|}
\hline & $\mathbf{3}$ months & $\mathbf{6}$ months & $\mathbf{9}$ months & 12 months \\
\hline All offices & & & & \\
\hline Placebo (2009-2011) & $-0.010^{* * *}$ & -0.004 & 0.000 & -0.001 \\
\hline & $(0.003)$ & $(0.005)$ & $(0.006)$ & $(0.007)$ \\
\hline & $n=31,667$ & $n=31,363$ & $n=31,255$ & $n=31,193$ \\
\hline & $0.016^{* * *}$ & $0.018^{* * *}$ & $0.016^{* *}$ & $0.024^{* *}$ \\
\hline & $(0.004)$ & $(0.007)$ & $(0.008)$ & $(0.009)$ \\
\hline Main (2011-2013) & $n=17,499$ & $n=17,321$ & $n=17,263$ & $n=17,233$ \\
\hline Buncrana, Letterkenny, Sligo, Westport & & & & \\
\hline Placebo (2009-2011) & -0.013 & -0.010 & $0.028 *$ & 0.007 \\
\hline & $(0.008)$ & $(0.013)$ & $(0.015)$ & $(0.017)$ \\
\hline Main (2011-2013) & $n=4,255$ & $n=4,206$ & $n=4,176$ & $n=4,165$ \\
\hline & 0.017 & 0.011 & -0.029 & -0.002 \\
\hline Nutgrove, Tallaght & $(0.013)$ & $(0.020)$ & $(0.023)$ & $(0.027)$ \\
\hline Placebo (2009-2011) & $n=2,239$ & $n=2,213$ & $n=2,196$ & $n=2,196$ \\
\hline & & & & \\
\hline & -0.004 & $-0.026 * *$ & $-0.051 * * *$ & $-0.038^{* * *}$ \\
\hline Main (2011-2013) & $(0.006)$ & $(0.011)$ & $(0.012)$ & $(0.015)$ \\
\hline & $n=6,485$ & $n=6,443$ & $n=6,423$ & $n=6,414$ \\
\hline & $0.017 * *$ & $0.031 * *$ & 0.019 & 0.027 \\
\hline & $(0.008)$ & $(0.014)$ & $(0.018)$ & $(0.020)$ \\
\hline
\end{tabular}

Authors' estimates.

This gives rise to the question of what specific states are contained in the 'other' category. To address this question, additional information was requested from the Department on the subcategories that it used to derive the 'other' outcome category. Based on the data received from the DEASP, there are over 150 subcategories in the 'other' category. These subcategories can be collapsed into three broader subcategories: (i) no longer entitled to unemployment, (ii) no reason stated/other, and iii) transferred to another Department scheme.

In Table 5.6, we show the distribution of individuals in the 'other' outcome category across these three headings. In calculating the distribution shown in Table 5.6, we combine all of the 'other' outcomes in the four time periods: three, six, nine and 12 months.

Approximately 34 per cent of the 'other' category is made up of individuals who are transferred to another DEASP scheme. We have no further information on approximately 32 per cent of this group, while 34 per cent are classified as being no longer entitled to unemployment. The results suggest that the procedural changes that accompanied the introduction of the Intreo activation process reforms resulted in the more effective early identification of individuals who were not entitled to, or were unsuitable for, unemployment assistance. As the Intreo reforms were principally process reforms, the results indicate important impacts 
in this area, i.e. in the efficient delivery of PES to jobseekers.

\begin{tabular}{|l|c|}
\hline \multicolumn{1}{c|}{ Outcome } & $\%$ \\
\hline No longer entitled to unemployment benefit & 34.4 \\
\hline No reason stated/other & 32.0 \\
\hline Transferred to other DEASP scheme & 33.6 \\
\hline
\end{tabular}

Source: Authors' estimates.

Given the finding from the DiD analysis for the 'other' outcome category, attention should be given to how the Intreo activation process reforms are interacting with the assignment of such outcome codes. However, it should be noted that compared to the other outcome categories (exits to employment, etc.), the number of 'other' cases is relatively small. ${ }^{35}$

We can also use the PSM-DiD framework to examine whether Intreo had any impact on the number of episodes we observe for an individual. Given that the underlying dataset used in the evaluation contains records from the first six months of the year, it is important to note that it is the number of episodes in the first six months of the year that we examine in Table 5.7.

Intreo had no effect on the number of episodes an individual was likely to have in the first six months of the year for both the baseline and geographically restricted models. In the baseline model, the placebo years show a small negative effect. This indicates that there was a greater increase in the number of episodes for individuals in control offices over the period 2009-2011 compared to those in treatment offices.

As stated previously, if this is a long-run trend, then the zero coefficient in our main model could potentially be interpreted as a positive effect. For example, it is possible that in the absence of the Intreo PES reforms, the trend observed in the 2009-2011 period could have continued into the 2011-2013 period, in which case we would have observed a statistically significant, positive coefficient. Therefore, it is possible that the absence of any effect in the treatment period actually reflects a positive effect which is offsetting the negative trend. However, as before, we do not have a sufficiently long time series to observe whether this was a long-run trend.

35 For example, in 2013, just 5 per cent of individuals were classified in the 'other' outcome category six months following their claim. This compares to 12 per cent in education or training, 32 per cent in employment and 51 per cent on the Live Register. 


\begin{tabular}{|l|l|}
\hline All offices & First 6 months of the year \\
\hline Placebo (2009-2011) & $-0.012 * * *$ \\
\hline & $(0.004)$ \\
\hline Main (2011-2013) & $n=30,985$ \\
\hline & 0.003 \\
\hline Buncrana, Letterkenny, Sligo, Westport & $(0.004)$ \\
\hline Placebo (2009-2011) & $n=17,097$ \\
\hline & -0.007 \\
\hline Main (2011-2013) & $(0.010)$ \\
\hline Nutgrove, Tallaght & $n=4,128$ \\
\hline Placebo (2009-2011) & 0.008 \\
\hline & $(0.011)$ \\
\hline Main (2011-2013) & $n=2,174$ \\
\hline & -0.005 \\
\hline & $(0.008)$ \\
\hline & $n=6,379$ \\
\hline & -0.007 \\
\hline & $(0.009)$ \\
\hline & $n=3,777$ \\
\hline
\end{tabular}

Source: Authors' estimates.

As an additional robustness check, we also report results from two additional specifications. The first excludes individuals with a Live Register history of greater than 50 days in duration and the second includes all individuals in the sample. The results are reported in appendix tables $\mathrm{A} 4$ to $\mathrm{A} 11$. These results are consistent with those presented above, namely that the Intreo reforms increased a claimant's probability of exiting the Live Register for 'other' reasons and increased the probability of going into employment three months following the start of the claim. 


\section{CHAPTER 6}

\section{Conclusion}

\subsection{THE EVALUATION}

The initial evaluation of the Intreo activation process reforms to Ireland's PES that is conducted in this report was undertaken using anonymised data provided by the DEASP from its Jobseeker Longitudinal Dataset (JLD). A difference-in-differences (DiD) methodology combined with propensity score matching (PSM) was used to conduct the evaluation.

\subsection{FINDINGS}

The main findings from this initial evaluation of the Intreo activation process reforms can be summarised as follows.

1. Based on the assignment of offices, it appears that the control group of offices are not a valid counterfactual to use in the DiD analysis. Significant effects were found in placebo years, which should not occur if the common trends assumption that underlies the DiD methodology was fulfilled; thus, this outcome (i.e. that the common trends assumption is not met when the full sample of offices are used to evaluate the Intreo reforms) should be taken into consideration when interpreting the evaluation results presented in this report.

2. We attempted to overcome this issue by focusing on treatment and control offices that were geographically close to each other. When we narrow the sample to offices which are geographically close and that pass the placebo tests, there is weak evidence that Intreo activation process reforms have increased the probability of jobseekers exiting the Live Register at six, nine and 12 months following an individual's initial claim.

3. There is weak evidence of an employment effect at six and nine months when we focus on the geographical sub-model of Buncrana, Letterkenny, Sligo and Westport offices, where individuals from Intreo offices were approximately 5 percentage points more likely to be in employment after six and nine months relative to individuals in the control offices.

4. The Intreo activation process reforms were found to have no impact on the probability of a jobseeker entering an education, training or employment placement course.

5. The Intreo reforms were also found to increase a claimant's probability of exiting to the 'other' category by approximately 2 percentage points. This result was 
found in the baseline model as well as the geographical sub-models. Thus, the overall result showing Intreo activation process reforms increasing a jobseeker's likelihood of exiting the Live Register appears to be predominantly driven by the 'other' exits.

6. No impact was found for the number of episodes that a claimant had in the first six months of the year.

\subsection{POLICY IMPLICATIONS}

It must be borne in mind that this evaluation was conducted at a time point early in the implementation of the new Intreo PES model; specifically, one year after the activation process reforms were introduced. Thus, at best, the evaluation can only establish the very short-run impacts of these reforms. The Intreo system was introduced to provide a more streamlined service to jobseekers in a one-stop-shop environment; this was a substantial departure from the previous NEAP PES system, under which employment services were split across a number of separate departments and agencies.

The Intreo PES system differs from the NEAP PES model in a number of other important respects, including: (1) the activation process began immediately and was underpinned by a principle of mutual obligation; (2) a profiling system was introduced to allow for different activation intensities depending on claimants' needs; and (3) more conditionality was applied to claims, with clearer guidelines for the imposition of penalties for non-compliance. Nevertheless, it is also important to stress that key elements of the activation process would have remained common to both the NEAP and Intreo PES systems; in particular, claimants' access to job search assistance and training opportunities would have remained relative similar across the two PES models. Given this, the introduction of the Intreo activation process reforms should be considered as a logical streamlining of benefit receipt and activation services rather than a fundamental overhaul of all the key components of PES functions, i.e. claim activation, job search assistance, monitoring, training provision and sanctions. Hence, the impacts of the introduction of the Intreo reforms on exits to employment are unlikely to be substantial and that initial effects are more likely to be observed in process and efficiency gains. The results of our evaluation generally confirm this to be the case.

In particular, the evaluation found that the introduction of Intreo had some marginal impacts on exits from the Live Register, with some more substantial impacts detected when the Live Register exit data were analysed at a more geographically disaggregated level. While the introduction of reforms had small positive impacts, at best, in terms of exits to employment and no discernible impact regarding exits to training, more substantial gains were observed regarding exits to 'other' outcomes. The 'other' category principally relates to individuals being identified as not qualifying or suitable for jobseeker payment assistance. 
Therefore, the results suggest that the reforms have led to the early identification of invalid unemployment claims, providing evidence of clear efficiency gains of having services delivered under a single point of contact. While this, and the finding that the reforms appear to have been effective in reducing the incidence of shortrun durations on the Live Register, are likely to give rise to savings to the Department, and ultimately the Exchequer, estimation of such savings is outside the scope of this study.

Some data and methodological issues need to be taken into account when interpreting the results. For the time period examined in this evaluation, we cannot rule out the possibility of pre-existing diverging trends between the outcomes of individuals in the treatment and control offices. This potentially invalidates the common trend assumption required for the DiD methodology. As mentioned above, we attempted to address this issue in our evaluation by selecting control and treatment offices that were in close geographical proximity to each other, and the approach proved to be successful in satisfying the common trends assumption that underlies the DiD methodology. It should also be noted that, where the data suggest, in the period preceding the recession exit rates were typically higher in the control offices, and if this occurred as part of a trend it is possible that the data may be downwardly biasing our programme estimates. However, we do not have sufficient data to validate or reject this possibility.

Finally, our analysis highlighted some issues with the roll-out of the profiling model. In particular, we found that 20 per cent of individuals in Intreo offices in 2013 did not have a PEX score. Also, for individuals for whom a PEX score was calculated, many had missing data for some of the questions required to calculate their PEX score. In theory, such claimants should have been given a zero PEX value, but this appears not to have been the case for all of them. Given that the PEX model is a key component of the Intreo PES model, and has been used by the Department to segment jobseekers into different categories (low, medium and high PEX) for engagement and intervention since 2012, further investigation is required as to how this tool has been implemented to date: in particular, to determine whether the model is being utilised to achieve the objectives that the system was initially designed and implemented to fulfil. 


\section{REFERENCES}

Blundell, R., M. Dias, C. Meghir, and J. Van Reenen (2004). 'Evaluating the employment impact of a mandatory job search program', Journal of the European Economic Association, Vol. 2, No. 4, pp. 569-606.

Borghi, V. and R. Van Berkel, (2007). 'New modes of governance in Italy and the Netherlands: the case of activation policies', Public Administration, Vol. 85, No. 1, pp. 83-101.

Centeno, L., M. Centeno, and A.A. Novo (2009). 'Evaluating job-search programs for old and young individuals: heterogeneous impact on unemployment duration', Labour Economics, Vol. 16, No. 1, pp. 12-25.

Department of Employment Affairs and Social Protection (2017). Pathways to Work 20162020, Dublin: DEASP.

Department of Public Expenditure and Reform (2017). Case study on Intreo: the one-stopshop for job seekers in Ireland, Dublin: DPER.

Department of Social Protection (2012). A Review of Department of Social Protection Employment Support Schemes, Dublin: DSP.

Grubb, D., S. Singh, and P. Tergeist (2009). Activation policies in Ireland, OECD Social, Employment and Migration Working Papers No. 75, Paris: OECD.

Hainmueller, J., B. Hofmann, G. Krug, and K. Wolf (2011). 'Do lower caseloads improve the effectiveness of active labor market policies? New evidence from German employment offices. LASER Discussion Paper, No. 52, University of ErlangenNuremberg.

Kelly, E., S. McGuinness, and J.R. Walsh (2015). An evaluation of the Back to Education Allowance, Research Series No. 47, Dublin: The Economic and Social Research Institute.

McGuinness, S., P.J. O'Connell, E. Kelly, and J. Walsh (2011). Activation in Ireland: an evaluation of the National Employment Action Plan, Research Series No. 20, Dublin: The Economic and Social Research Institute.

Minas, R. (2014). 'One-stop shops: increasing employability and overcoming welfare state fragmentation?', International Journal of Social Welfare, Vol. 23, pp. 40-53.

O'Connell, P.J., S. McGuinness, E. Kelly, and J. R. Walsh (2009). National profiling of the unemployed in Ireland, Research Series No. 10, Dublin: The Economic and Social Research Institute.

Reis, M. (2015). 'Vocational training and labor market outcomes in Brazil', BE Journal of Economic Analysis \& Policy, Vol. 15, No. 1, pp. 377-405.

Rosenbaum, P.R. and D.B. Rubin (1983). 'The central role of the propensity score in observational studies for causal effects', Biometrika, Vol. 70, No. 1, pp. 41-55. 
Stenberg, A. and O. Westerlund (2015). 'The long-term earnings consequences of general vs. specific training of the unemployed', IZA Journal of European Labor Studies, Vol. 4, No. 1, pp. 1-26.

Stuart E., H. Huskamp, K. Duckworth, J. Simmons, Z. Song, M. Chernew, and C. Barry (2014). 'Using propensity scores in difference-in-differences models to estimate the effects of a policy change', Health Services and Outcomes Research Methodology, Vol. 14, No. 4, pp. 166-182.

Van Berkel, R. (2010). 'The provision of income protection and activation services for the unemployed in "active" welfare states. an international comparison', Journal of Social Policy, Vol. 39, No. 1, pp. 17-34. 


\section{APPENDIX}

TABLE A1 DIFFERENCES IN PERSONAL CHARACTERISTICS AMONG TREATMENT AND CONTROL GROUPS

\begin{tabular}{|c|c|c|c|c|c|c|}
\hline & $\begin{array}{l}\text { Treatment } \\
\text { Group } \\
(2011)\end{array}$ & $\begin{array}{l}\text { Control } \\
\text { Group } \\
(2011)\end{array}$ & $\begin{array}{c}\text { P-Value } \\
\text { (Difference) }\end{array}$ & $\begin{array}{c}\text { Treatment } \\
\text { Group } \\
(2013)\end{array}$ & $\begin{array}{l}\text { Control } \\
\text { Group } \\
(2013)\end{array}$ & $\begin{array}{c}\text { P-Value } \\
\text { (Difference) }\end{array}$ \\
\hline Male & $53.8 \%$ & $55.0 \%$ & 0.220 & $50.0 \%$ & $49.5 \%$ & 0.671 \\
\hline Age (years) & 32.4 & 32.1 & 0.309 & 32.6 & 33.3 & 0.023 \\
\hline Irish national & $78.2 \%$ & $80.0 \%$ & 0.038 & $76.3 \%$ & $80.0 \%$ & 0.000 \\
\hline $\begin{array}{l}\text { Average number } \\
\text { of dependent } \\
\text { children }\end{array}$ & 0.25 & 0.25 & 0.900 & 0.28 & 0.27 & 0.404 \\
\hline $\begin{array}{l}\text { Number of pre- } \\
\text { event employment } \\
\text { events }\end{array}$ & 1.8 & 2.1 & 0.000 & 1.7 & 2.0 & 0.000 \\
\hline $\begin{array}{l}\text { Duration of pre- } \\
\text { event employment } \\
\text { events (days) }\end{array}$ & 1941 & 2056 & 0.005 & 1950 & 2219 & 0.000 \\
\hline \multicolumn{7}{|l|}{ Marital status } \\
\hline Married & $30.8 \%$ & $33.7 \%$ & 0.002 & $29.9 \%$ & $31.8 \%$ & 0.071 \\
\hline Cohabiting & $6.1 \%$ & $5.4 \%$ & 0.116 & $4.6 \%$ & $5.0 \%$ & 0.418 \\
\hline Separated & $4.4 \%$ & $4.0 \%$ & 0.285 & $5.2 \%$ & $4.6 \%$ & 0.166 \\
\hline Single & $57.1 \%$ & $55.7 \%$ & 0.150 & $58.9 \%$ & $57.5 \%$ & 0.230 \\
\hline Widow & $1.1 \%$ & $1.0 \%$ & 0.692 & $0.5 \%$ & $0.6 \%$ & 0.297 \\
\hline Unknown & $0.5 \%$ & $0.3 \%$ & 0.044 & $0.9 \%$ & $0.5 \%$ & 0.018 \\
\hline \multicolumn{7}{|l|}{ Occupation } \\
\hline Managers & $7.0 \%$ & $7.4 \%$ & 0.453 & $9.4 \%$ & $9.7 \%$ & 0.648 \\
\hline Professionals & $8.2 \%$ & $11.5 \%$ & 0.000 & $7.6 \%$ & $12.5 \%$ & 0.000 \\
\hline $\begin{array}{l}\text { Associate } \\
\text { professionals }\end{array}$ & $5.2 \%$ & $5.1 \%$ & 0.846 & $5.5 \%$ & $5.4 \%$ & 0.776 \\
\hline Clerical & $13.9 \%$ & $9.7 \%$ & 0.000 & $11.0 \%$ & $9.0 \%$ & 0.004 \\
\hline Skilled trades & $15.0 \%$ & $14.0 \%$ & 0.162 & $10.7 \%$ & $10.1 \%$ & 0.350 \\
\hline Other services & $12.2 \%$ & $10.6 \%$ & 0.013 & $11.0 \%$ & $12.1 \%$ & 0.146 \\
\hline Sales & $13.1 \%$ & $16.6 \%$ & 0.000 & $11.5 \%$ & $14.4 \%$ & 0.000 \\
\hline Operatives & $9.8 \%$ & $10.0 \%$ & 0.668 & $9.1 \%$ & $10.7 \%$ & 0.022 \\
\hline Elementary & $15.7 \%$ & $15.0 \%$ & 0.352 & $24.2 \%$ & $16.2 \%$ & 0.000 \\
\hline \multicolumn{7}{|l|}{ Earnings of spouse } \\
\hline $\mathrm{Nil}$ & $14.0 \%$ & $14.0 \%$ & 0.926 & $12.9 \%$ & $13.2 \%$ & 0.693 \\
\hline Not applicable & $67.1 \%$ & $66.0 \%$ & 0.240 & $67.0 \%$ & $64.6 \%$ & 0.027 \\
\hline$<€ 100$ & $0.1 \%$ & $0.1 \%$ & 0.785 & $0.1 \%$ & $0.2 \%$ & 0.210 \\
\hline$€ 100-€ 310$ & $1.0 \%$ & $0.8 \%$ & 0.416 & $0.6 \%$ & $0.8 \%$ & 0.359 \\
\hline$€ 310-€ 400$ & $1.6 \%$ & $1.9 \%$ & 0.268 & $1.5 \%$ & $1.5 \%$ & 0.818 \\
\hline$€ 400+$ & $10.3 \%$ & $10.7 \%$ & 0.481 & $10.5 \%$ & $13.6 \%$ & 0.000 \\
\hline Details Unknown & $6.0 \%$ & $6.5 \%$ & 0.309 & $7.4 \%$ & $6.2 \%$ & 0.025 \\
\hline Observations & $n=4478$ & $n=5320$ & & $n=3936$ & $n=3968$ & \\
\hline
\end{tabular}




\begin{tabular}{|c|c|c|c|c|c|c|}
\hline & $\begin{array}{c}\text { Treatment } \\
\text { Group } \\
\text { (2011) }\end{array}$ & $\begin{array}{l}\text { Treatment } \\
\text { Group } \\
(2013)\end{array}$ & $\begin{array}{c}\text { P-Value } \\
\text { (Difference) }\end{array}$ & $\begin{array}{l}\text { Control } \\
\text { Group } \\
(2011)\end{array}$ & $\begin{array}{l}\text { Control } \\
\text { Group } \\
(2013)\end{array}$ & $\begin{array}{c}\text { P-Value } \\
\text { (Difference) }\end{array}$ \\
\hline Male & $53.8 \%$ & $50.0 \%$ & 0.001 & $55.0 \%$ & $49.5 \%$ & 0.000 \\
\hline Age (years) & 32.4 & 32.6 & 0.411 & 32.1 & 33.3 & 0.000 \\
\hline Irish national & $78.2 \%$ & $76.3 \%$ & 0.033 & $80.0 \%$ & $80.0 \%$ & 0.974 \\
\hline $\begin{array}{l}\text { Average number } \\
\text { of dependent } \\
\text { children }\end{array}$ & 0.25 & 0.28 & 0.049 & 0.25 & 0.27 & 0.287 \\
\hline $\begin{array}{l}\text { Number of pre- } \\
\text { event employment } \\
\text { events }\end{array}$ & 1.8 & 1.7 & 0.001 & 2.1 & 2.0 & 0.216 \\
\hline $\begin{array}{l}\text { Duration of pre- } \\
\text { event employment } \\
\text { events (days) }\end{array}$ & 1941 & 1950 & 0.847 & 2056 & 2219 & 0.001 \\
\hline \multicolumn{7}{|l|}{ Marital status } \\
\hline Married & $30.8 \%$ & $29.9 \%$ & 0.399 & $33.7 \%$ & $31.8 \%$ & 0.051 \\
\hline Cohabiting & $6.1 \%$ & $4.6 \%$ & 0.003 & $5.4 \%$ & $5.0 \%$ & 0.497 \\
\hline Separated & $4.4 \%$ & $5.2 \%$ & 0.074 & $4.0 \%$ & $4.6 \%$ & 0.158 \\
\hline Single & $57.1 \%$ & $58.9 \%$ & 0.106 & $55.7 \%$ & $57.5 \%$ & 0.074 \\
\hline Widow & $1.1 \%$ & $0.5 \%$ & 0.001 & $1.0 \%$ & $0.6 \%$ & 0.037 \\
\hline Unknown & $0.5 \%$ & $0.9 \%$ & 0.038 & $0.3 \%$ & $0.5 \%$ & 0.121 \\
\hline \multicolumn{7}{|l|}{ Occupation } \\
\hline Managers & $7.0 \%$ & $9.4 \%$ & 0.000 & $7.4 \%$ & $9.7 \%$ & 0.000 \\
\hline Professionals & $8.2 \%$ & $7.6 \%$ & 0.307 & $11.5 \%$ & $12.5 \%$ & 0.141 \\
\hline $\begin{array}{l}\text { Associate } \\
\text { professionals }\end{array}$ & $5.2 \%$ & $5.5 \%$ & 0.499 & $5.1 \%$ & $5.4 \%$ & 0.557 \\
\hline Clerical & $13.9 \%$ & $11.0 \%$ & 0.000 & $9.7 \%$ & $9.0 \%$ & 0.261 \\
\hline Skilled trades & $15.0 \%$ & $10.7 \%$ & 0.000 & $14.0 \%$ & $10.1 \%$ & 0.000 \\
\hline Other services & $12.2 \%$ & $11.0 \%$ & 0.090 & $10.6 \%$ & $12.1 \%$ & 0.029 \\
\hline Sales & $13.1 \%$ & $11.5 \%$ & 0.020 & $16.6 \%$ & $14.4 \%$ & 0.003 \\
\hline Operatives & $9.8 \%$ & $9.1 \%$ & 0.339 & $10.0 \%$ & $10.7 \%$ & 0.296 \\
\hline Elementary & $15.7 \%$ & $24.2 \%$ & 0.000 & $15.0 \%$ & $16.2 \%$ & 0.127 \\
\hline Observations & $n=4478$ & $n=3936$ & & $n=5320$ & $n=3968$ & \\
\hline
\end{tabular}




\begin{tabular}{|c|c|c|c|c|c|c|c|c|}
\hline & \multicolumn{4}{|c|}{ Unmatched } & \multicolumn{4}{|c|}{ Matched } \\
\hline & $\begin{array}{l}\text { Treated } \\
\text { in } 2011\end{array}$ & $\begin{array}{l}\text { Treated } \\
\text { in } 2013\end{array}$ & $\begin{array}{l}\text { Control } \\
\text { in } 2011\end{array}$ & $\begin{array}{l}\text { Control } \\
\text { in } 2013\end{array}$ & $\begin{array}{l}\text { Treated } \\
\text { in } 2011\end{array}$ & $\begin{array}{l}\text { Treated } \\
\text { in } 2013\end{array}$ & $\begin{array}{l}\text { Control } \\
\text { in } 2011\end{array}$ & $\begin{array}{l}\text { Control } \\
\text { in } 2013\end{array}$ \\
\hline Male & $53.8 \%$ & $50.0 \%$ & $55.0 \%$ & $49.5 \%$ & $53.8 \%$ & $54.2 \%$ & $53.7 \%$ & $53.5 \%$ \\
\hline Age (years) & 32.4 & 32.6 & 32.1 & 33.3 & 32.4 & 32.4 & 32.5 & 32.4 \\
\hline \multicolumn{9}{|l|}{ Marital status } \\
\hline Married & $30.7 \%$ & $29.9 \%$ & $33.7 \%$ & $31.8 \%$ & $30.8 \%$ & $30.7 \%$ & $30.7 \%$ & $30.7 \%$ \\
\hline Cohabits & $6.1 \%$ & $4.7 \%$ & $5.4 \%$ & $5.0 \%$ & $6.1 \%$ & $5.9 \%$ & $6.3 \%$ & $6.2 \%$ \\
\hline Separated & $4.4 \%$ & $5.2 \%$ & $4.0 \%$ & $4.6 \%$ & $4.4 \%$ & $4.5 \%$ & $4.5 \%$ & $4.4 \%$ \\
\hline Single & $57.1 \%$ & $58.9 \%$ & $55.7 \%$ & $57.5 \%$ & $57.1 \%$ & $57.3 \%$ & $56.8 \%$ & $57.2 \%$ \\
\hline Widow & $1.1 \%$ & $0.5 \%$ & $1.0 \%$ & $0.6 \%$ & $1.1 \%$ & $1.2 \%$ & $1.1 \%$ & $1.1 \%$ \\
\hline Unknown & $0.5 \%$ & $0.9 \%$ & $0.3 \%$ & $0.5 \%$ & $0.5 \%$ & $0.5 \%$ & $0.6 \%$ & $0.5 \%$ \\
\hline \multicolumn{9}{|l|}{ Occupation } \\
\hline Manager & $7.0 \%$ & $9.4 \%$ & $7.4 \%$ & $9.7 \%$ & $7.0 \%$ & $7.1 \%$ & $7.1 \%$ & $6.9 \%$ \\
\hline Professional & $8.2 \%$ & $7.6 \%$ & $11.5 \%$ & $12.5 \%$ & $8.2 \%$ & $8.2 \%$ & $8.2 \%$ & $8.2 \%$ \\
\hline $\begin{array}{l}\text { Associate } \\
\text { professional }\end{array}$ & $5.2 \%$ & $5.5 \%$ & $5.1 \%$ & $5.4 \%$ & $5.2 \%$ & $5.2 \%$ & $5.1 \%$ & $5.3 \%$ \\
\hline Clerical & $13.9 \%$ & $11.0 \%$ & $9.7 \%$ & $9.1 \%$ & $13.9 \%$ & $13.9 \%$ & $14.0 \%$ & $13.5 \%$ \\
\hline Skilled trades & $15.0 \%$ & $10.7 \%$ & $14.0 \%$ & $10.1 \%$ & $15.0 \%$ & $14.8 \%$ & $15.1 \%$ & $15.1 \%$ \\
\hline Other services & $12.2 \%$ & $11.0 \%$ & $10.6 \%$ & $12.1 \%$ & $12.2 \%$ & $12.1 \%$ & $12.1 \%$ & $12.2 \%$ \\
\hline Sales & $13.1 \%$ & $11.5 \%$ & $16.6 \%$ & $14.4 \%$ & $13.1 \%$ & $13.3 \%$ & $13.2 \%$ & $13.1 \%$ \\
\hline Operatives & $9.8 \%$ & $9.2 \%$ & $10.0 \%$ & $10.7 \%$ & $9.8 \%$ & $9.6 \%$ & $9.7 \%$ & $9.9 \%$ \\
\hline Elementary & $15.7 \%$ & $24.2 \%$ & $15.0 \%$ & $16.2 \%$ & $15.7 \%$ & $15.6 \%$ & $15.6 \%$ & $15.8 \%$ \\
\hline \multicolumn{9}{|l|}{ Earnings of spouse } \\
\hline Nil & $14.0 \%$ & $12.9 \%$ & $14.0 \%$ & $13.2 \%$ & $14.0 \%$ & $14.2 \%$ & $14.0 \%$ & $14.4 \%$ \\
\hline Not applicable & $67.1 \%$ & $67.0 \%$ & $66.0 \%$ & $64.6 \%$ & $67.1 \%$ & $66.9 \%$ & $66.8 \%$ & $66.4 \%$ \\
\hline$<€ 100$ & $0.1 \%$ & $0.1 \%$ & $0.1 \%$ & $0.2 \%$ & $0.1 \%$ & $0.1 \%$ & $0.1 \%$ & $0.1 \%$ \\
\hline$€ 100-€ 310$ & $1.0 \%$ & $0.6 \%$ & $0.8 \%$ & $0.8 \%$ & $1.0 \%$ & $1.0 \%$ & $1.0 \%$ & $1.0 \%$ \\
\hline$€ 310-€ 400$ & $1.6 \%$ & $1.5 \%$ & $1.9 \%$ & $1.5 \%$ & $1.6 \%$ & $1.6 \%$ & $1.7 \%$ & $1.7 \%$ \\
\hline$€ 400+$ & $10.3 \%$ & $10.5 \%$ & $10.7 \%$ & $13.6 \%$ & $10.3 \%$ & $10.1 \%$ & $10.3 \%$ & $10.3 \%$ \\
\hline Details Unknown & $6.0 \%$ & $7.4 \%$ & $6.5 \%$ & $6.2 \%$ & $6.0 \%$ & $6.1 \%$ & $6.1 \%$ & $6.2 \%$ \\
\hline
\end{tabular}

Source: Authors' estimates.

Note: $\quad$ The weighted descriptive statistics use the propensity score weights, which use the 'treated in 2011' group as the base case against which the other three groups are matched. As such, the descriptive statistics across the four groups are more similar for the weighted measure compared to the unweighted measure. 
TABLE A4 INDIVIDUALS WITH A LIVE REGISTER HISTORY OF LESS THAN 50 DAYS' DURATION: DID COEFFICIENTS FROM PSM-DID ANALYSIS OF PROBABILITY OF EXITING THE LIVE REGISTER

\begin{tabular}{|l|c|c|c|c|c|}
\hline & $\mathbf{3}$ months & $\mathbf{6}$ months & $\mathbf{9}$ months & $\mathbf{1 2}$ months \\
\hline All offices & & & & \\
\hline & $-0.041 * *$ & $-0.031 * * *$ & $-0.036 * * *$ & $-0.022 *$ \\
\hline Placebo (2009-2011) & $(0.010)$ & $(0.011)$ & $(0.012)$ & $(0.012)$ \\
\hline & $n=25,850$ & $n=25,616$ & $n=25,536$ & $n=25,477$ \\
\hline Main (2011-2013) & $0.048 * *$ & $0.044 * * *$ & $0.038 * *$ & 0.017 \\
\hline & $(0.013)$ & $(0.015)$ & $(0.016)$ & $(0.016)$ \\
\hline Buncrana, Letterkenny, Sligo, Westport & $n=14,978$ & $n=14,820$ & $n=14,767$ & $n=14,734$ \\
\hline Placebo (2009-2011) & 0.022 & -0.008 & 0.021 & 0.032 \\
\hline & $(0.024)$ & $(0.029)$ & $(0.030)$ & $(0.030)$ \\
\hline Main (2011-2013) & $n=3,825$ & $n=3,786$ & $n=3,762$ & $n=3,748$ \\
\hline & 0.018 & 0.028 & -0.006 & -0.040 \\
\hline Nutgrove, Tallaght & $(0.033)$ & $(0.041)$ & $(0.042)$ & $(0.042)$ \\
\hline Placebo (2009-2011) & $n=2,092$ & $n=2,069$ & $n=2,055$ & $n=2,054$ \\
\hline & & & & \\
\hline
\end{tabular}

Source: Authors' estimates. 
TABLE A5 INDIVIDUALS WITH A LIVE REGISTER HISTORY OF LESS THAN 50 DAYS' DURATION: PSM-DID ANALYSIS OF PROBABILITY OF BEING IN EMPLOYMENT

\begin{tabular}{|l|c|c|c|c|c|}
\hline & $\mathbf{3}$ months & $\mathbf{6}$ months & $\mathbf{9}$ months & $\mathbf{1 2}$ months \\
\hline All offices & & & & \\
\hline & $-0.035 * * *$ & $-0.027 * *$ & $-0.036 * *$ & -0.018 \\
\hline Placebo (2009-2011) & $(0.009)$ & $(0.011)$ & $(0.011)$ & $(0.011)$ \\
\hline & $n=25,850$ & $n=25,616$ & $n=25,536$ & $n=25,477$ \\
\hline Main (2011-2013) & $0.036 * * *$ & 0.020 & 0.015 & -0.003 \\
\hline & $(0.012)$ & $(0.014)$ & $(0.014)$ & $(0.015)$ \\
\hline Buncrana, Letterkenny, Sligo, Westport & $n=14,978$ & $n=14,820$ & $n=14,767$ & $n=14,734$ \\
\hline Placebo (2009-2011) & $0.039 *$ & -0.013 & -0.014 & 0.003 \\
\hline Main (2011-2013) & $(0.021)$ & $(0.025)$ & $(0.026)$ & $(0.027)$ \\
\hline & $n=3,825$ & $n=3,786$ & $n=3,762$ & $n=3,748$ \\
\hline Nutgrove, Tallaght & -0.003 & 0.048 & 0.025 & -0.015 \\
\hline Placebo (2009-2011) & $(0.028)$ & $(0.034)$ & $(0.035)$ & $(0.036)$ \\
\hline & $n=2,092$ & $n=2,069$ & $n=2,055$ & $n=2,054$ \\
\hline
\end{tabular}

Source: $\quad$ Authors' estimates. 
TABLE A6 INDIVIDUALS WITH A LIVE REGISTER HISTORY OF LESS THAN 50 DAYS' DURATION: PSM-DID ANALYSIS OF PROBABILITY OF BEING IN EDUCATION, TRAINING OR EMPLOYMENT PLACEMENT COURSE

\begin{tabular}{|c|c|c|c|c|}
\hline & 3 months & 6 months & 9 months & 12 months \\
\hline \multicolumn{5}{|l|}{ All offices } \\
\hline \multirow[t]{3}{*}{ Placebo (2009-2011) } & -0.003 & -0.003 & 0.001 & -0.003 \\
\hline & $(0.003)$ & $(0.005)$ & $(0.006)$ & $(0.005)$ \\
\hline & $n=25,850$ & $n=25,616$ & $n=25,536$ & $n=25,477$ \\
\hline \multirow[t]{3}{*}{ Main (2011-2013) } & -0.001 & 0.004 & 0.000 & -0.007 \\
\hline & $(0.005)$ & $(0.008)$ & $(0.009)$ & (0.009) \\
\hline & $n=14,978$ & $n=14,820$ & $n=14,767$ & $n=14,734$ \\
\hline \multicolumn{5}{|c|}{ Buncrana, Letterkenny, Sligo, Westport } \\
\hline \multirow[t]{3}{*}{ Placebo (2009-2011) } & -0.008 & 0.019 & 0.022 & 0.008 \\
\hline & $(0.009)$ & $(0.015)$ & $(0.016)$ & $(0.015)$ \\
\hline & $n=3,825$ & $n=3,786$ & $n=3,762$ & $n=3,748$ \\
\hline \multirow[t]{3}{*}{ Main (2011-2013) } & 0.001 & $-0.046^{*}$ & -0.023 & -0.025 \\
\hline & $(0.015)$ & $(0.025)$ & $(0.028)$ & $(0.026)$ \\
\hline & $n=2,092$ & $n=2,069$ & $n=2,055$ & $n=2,054$ \\
\hline \multicolumn{5}{|l|}{ Nutgrove, Tallaght } \\
\hline \multirow[t]{3}{*}{ Placebo (2009-2011) } & 0.001 & -0.013 & -0.009 & 0.013 \\
\hline & $(0.007)$ & $(0.009)$ & $(0.012)$ & $(0.012)$ \\
\hline & $n=5,069$ & $n=5,039$ & $n=5,029$ & $n=5,019$ \\
\hline \multirow[t]{3}{*}{ Main (2011-2013) } & -0.012 & 0.006 & $0.033^{*}$ & 0.007 \\
\hline & $(0.009)$ & $(0.015)$ & $(0.018)$ & $(0.017)$ \\
\hline & $n=3,161$ & $n=3,132$ & $n=3,125$ & $n=3,112$ \\
\hline
\end{tabular}


TABLE A7 INDIVIDUALS WITH A LIVE REGISTER HISTORY OF LESS THAN 50 DAYS' DURATION: PSM-DID ANALYSIS OF PROBABILITY OF BEING IN ‘OTHER' OUTCOME CATEGORY

\begin{tabular}{|l|c|c|c|c|c|}
\hline & $\mathbf{3}$ months & $\mathbf{6}$ months & $\mathbf{9}$ months & $\mathbf{1 2}$ months \\
\hline All offices & & & & \\
\hline & -0.004 & -0.002 & -0.001 & -0.002 \\
\hline Placebo (2009-2011) & $(0.003)$ & $(0.005)$ & $(0.006)$ & $(0.007)$ \\
\hline & $n=25,850$ & $n=25,616$ & $n=25,536$ & $n=25,477$ \\
\hline Main (2011-2013) & $0.013 * * *$ & $0.020 * * *$ & $0.023 * * *$ & $0.027 * * *$ \\
\hline & $(0.004)$ & $(0.007)$ & $(0.009)$ & $(0.010)$ \\
\hline Buncrana, Letterkenny, Sligo, Westport & $n=14,978$ & $n=14,820$ & $n=14,767$ & $n=14,734$ \\
\hline Placebo (2009-2011) & -0.010 & -0.014 & 0.013 & 0.021 \\
\hline & $(0.009)$ & $(0.013)$ & $(0.015)$ & $(0.017)$ \\
\hline Main (2011-2013) & $n=3,825$ & $n=3,786$ & $n=3,762$ & $n=3,748$ \\
\hline & 0.019 & 0.026 & -0.009 & 0.000 \\
\hline Nutgrove, Tallaght & $(0.014)$ & $(0.020)$ & $(0.023)$ & $(0.026)$ \\
\hline Placebo (2009-2011) & $n=2,092$ & $n=2,069$ & $n=2,055$ & $n=2,054$ \\
\hline & & & & \\
\hline
\end{tabular}

Source: $\quad$ Authors' estimates. 

REGISTER (FULL SAMPLE)

\begin{tabular}{|l|c|c|c|c|c|}
\hline & $\mathbf{3}$ months & $\mathbf{6}$ months & $\mathbf{9}$ months & $\mathbf{1 2}$ months \\
\hline All offices & & & & \\
\hline & $-0.026^{* * *}$ & $-0.023^{* * *}$ & $-0.027^{* * *}$ & $-0.017^{*}$ \\
\hline & $(0.007)$ & $(0.008)$ & $(0.009)$ & $(0.009)$ \\
\hline Placebo (2009-2011) & $n=48,330$ & $n=47,973$ & $n=47,820$ & $n=47,706$ \\
\hline & $0.024^{* * *}$ & $0.033^{* * *}$ & $0.030^{* * *}$ & 0.015 \\
\hline & $(0.008)$ & $(0.010)$ & $(0.010)$ & $(0.010)$ \\
\hline Main (2011-2013) & $n=38,118$ & $n=37,829$ & $n=37,673$ & $n=37,573$ \\
\hline Buncrana, Letterkenny, Sligo, Westport & & & & \\
\hline Placebo (2009-2011) & -0.005 & -0.003 & -0.017 & 0.013 \\
\hline & $(0.017)$ & $(0.020)$ & $(0.021)$ & $(0.021)$ \\
\hline Main (2011-2013) & $n=7,769$ & $n=7,697$ & $n=7,657$ & $n=7,628$ \\
\hline & 0.028 & $0.054^{* *}$ & $0.068^{* * *}$ & 0.025 \\
\hline Nutgrove, Tallaght & $(0.021)$ & $(0.025)$ & $(0.025)$ & $(0.025)$ \\
\hline Placebo (2009-2011) & $n=5,859$ & $n=5,798$ & $n=5,765$ & $n=5,747$ \\
\hline & & & & \\
\hline Main (2011-2013) & -0.005 & -0.017 & -0.013 & -0.002 \\
\hline & $(0.015)$ & $(0.019)$ & $(0.019)$ & $(0.019)$ \\
\hline & $n=9,191$ & $n=9,153$ & $n=9,134$ & $n=9,117$ \\
\hline & -0.001 & 0.034 & $0.061^{* * *}$ & $0.047 * *$ \\
\hline
\end{tabular}

Source: Authors' estimates.

TABLE A9 PSM-DID ANALYSIS OF PROBABILITY OF BEING IN EMPLOYMENT (FULL SAMPLE)

\begin{tabular}{|c|c|c|c|c|}
\hline & $\mathbf{3}$ months & $\mathbf{6}$ months & $\mathbf{9}$ months & $\mathbf{1 2}$ months \\
\hline All offices & & & & \\
\hline Placebo (2009-2011) & $-0.025^{* * *}$ & $-0.019^{* *}$ & $-0.023^{* * *}$ & -0.008 \\
\hline & $(0.007)$ & $(0.008)$ & $(0.008)$ & $(0.008)$ \\
\hline & $n=48,330$ & $n=47,973$ & $n=47,820$ & $n=47,706$ \\
\hline Main (2011-2013) & $0.019^{* *}$ & 0.015 & 0.004 & -0.007 \\
\hline & $(0.008)$ & $(0.009)$ & $(0.009)$ & $(0.009)$ \\
\hline & $n=38,118$ & $n=37,829$ & $n=37,673$ & $n=37,573$ \\
\hline Buncrana, Letterkenny, Sligo, Westport & & & & \\
\hline Placebo (2009-2011) & -0.013 & -0.011 & -0.028 & -0.008 \\
\hline & $(0.016)$ & $(0.018)$ & $(0.019)$ & $(0.019)$ \\
\hline Main (2011-2013) & $n=7,769$ & $n=7,697$ & $n=7,657$ & $n=7,628$ \\
\hline & 0.026 & $0.048^{* *}$ & $0.056 * *$ & 0.027 \\
\hline Nutgrove, Tallaght & $(0.019)$ & $(0.022)$ & $(0.023)$ & $(0.023)$ \\
\hline Placebo (2009-2011) & $n=5,859$ & $n=5,798$ & $n=5,765$ & $n=5,747$ \\
& & & & \\
\hline & -0.007 & -0.008 & -0.000 & -0.006 \\
\hline Main (2011-2013) & $(0.014)$ & $(0.017)$ & $(0.018)$ & $(0.018)$ \\
\hline & $n=9,191$ & 9,153 & $n=9,134$ & $n=9,117$ \\
\hline & -0.020 & 0.008 & 0.010 & 0.021 \\
\hline & $(0.017)$ & $(0.020)$ & $(0.021)$ & $(0.021)$ \\
\hline & $n=7,568$ & $n=7,526$ & $n=7,500$ & $n=7,473$ \\
\hline
\end{tabular}


TABLE A10 PSM-DID ANALYSIS OF PROBABILITY OF BEING IN EDUCATION, TRAINING OR EMPLOYMENT PLACEMENT COURSE (FULL SAMPLE)

\begin{tabular}{|l|c|c|c|c|c|}
\hline & $\mathbf{3}$ months & $\mathbf{6}$ months & $\mathbf{9}$ months & $\mathbf{1 2}$ months \\
\hline All offices & & & & \\
\hline & 0.002 & 0.002 & 0.001 & -0.003 \\
\hline Placebo (2009-2011) & $(0.002)$ & $(0.004)$ & $(0.004)$ & 0.004 \\
\hline & $n=48,330$ & $n=47,973$ & $n=47,820$ & $n=47,706$ \\
\hline Main (2011-2013) & -0.003 & 0.003 & 0.006 & 0.003 \\
\hline & $(0.003)$ & $(0.005)$ & $(0.005)$ & $(0.005)$ \\
\hline Buncrana, Letterkenny, Sligo, Westport & $n=38,118$ & $n=37,829$ & $n=37,673$ & $n=37,573$ \\
\hline Placebo (2009-2011) & $0.014 * *$ & 0.016 & 0.007 & 0.004 \\
\hline & $(0.006)$ & $(0.010)$ & $(0.011)$ & $(0.011)$ \\
\hline Main (2011-2013) & $n=7,769$ & $n=7,697$ & $n=7,657$ & $n=7,628$ \\
\hline & -0.007 & -0.010 & 0.006 & 0.003 \\
\hline Nutgrove, Tallaght & $(0.008)$ & $(0.013)$ & $(0.015)$ & $(0.014)$ \\
\hline Placebo (2009-2011) & $n=5,859$ & $n=5,798$ & $n=5,765$ & $n=5,747$ \\
\hline & & & & \\
\hline
\end{tabular}

Source: Authors' estimates.

TABLE A11 PSM-DID ANALYSIS OF PROBABILITY OF BEING IN 'OTHER' OUTCOME CATEGORY (FULL SAMPLE)

\begin{tabular}{|c|c|c|c|c|}
\hline & 3 months & 6 months & 9 months & 12 months \\
\hline \multicolumn{5}{|l|}{ All offices } \\
\hline \multirow{3}{*}{ Placebo (2009-2011) } & -0.003 & $-0.006^{*}$ & -0.006 & -0.006 \\
\hline & $(0.002)$ & $(0.004)$ & $(0.004)$ & $(0.005)$ \\
\hline & $n=48,330$ & $n=47,973$ & $n=47,820$ & $n=47,706$ \\
\hline \multirow[t]{3}{*}{ Main (2011-2013) } & $0.008^{* *}$ & $0.016^{* * *}$ & $0.019 * * *$ & $0.019 * * *$ \\
\hline & $(0.003)$ & $(0.005)$ & $(0.005)$ & $(0.006)$ \\
\hline & $n=38,118$ & $n=37,829$ & $n=37,673$ & $n=37,573$ \\
\hline \multicolumn{5}{|c|}{ Buncrana, Letterkenny, Sligo, Westport } \\
\hline \multirow[t]{3}{*}{ Placebo (2009-2011) } & -0.006 & -0.008 & 0.004 & 0.018 \\
\hline & $(0.007)$ & (0.009) & (0.010) & $(0.012)$ \\
\hline & $n=7,769$ & $n=6,697$ & $n=7,657$ & $n=7,628$ \\
\hline \multirow[t]{3}{*}{ Main (2011-2013) } & 0.009 & 0.016 & 0.006 & -0.006 \\
\hline & (0.008) & (0.012) & $(0.013)$ & (0.015) \\
\hline & $n=5,859$ & $n=5,798$ & $n=5,765$ & $n=5,747$ \\
\hline \multicolumn{5}{|l|}{ Nutgrove, Tallaght } \\
\hline \multirow[t]{3}{*}{ Placebo (2009-2011) } & -0.003 & 0.007 & -0.006 & -0.005 \\
\hline & $(0.005)$ & $(0.008)$ & (0.009) & $(0.011)$ \\
\hline & $n=9,191$ & $n=9,153$ & $n=9,134$ & $n=9,117$ \\
\hline \multirow[t]{3}{*}{ Main (2011-2013) } & $0.012 * *$ & $0.016^{*}$ & 0.019* & 0.019 \\
\hline & $(0.006)$ & (0.009) & $(0.011)$ & $(0.012)$ \\
\hline & $n=7,568$ & $n=7,526$ & $n=7,500$ & $n=7,473$ \\
\hline
\end{tabular}


Whitaker Square,

Sir John Rogerson's Quay, Dublin 2

Telephone +35318632000

Email admin@esri.ie

Web www.esri.ie

Twitter @ESRIDublin

ISBN 978-0-7070-0472-3 